Boston University School of Law

Scholarly Commons at Boston University School of Law

Faculty Scholarship

10-1-2015

\title{
The Way We Pay Now: Understanding and Evaluating Performance-Based Executive Pay
}

David I. Walker

Boston University School of Law

Follow this and additional works at: https://scholarship.law.bu.edu/faculty_scholarship

Part of the Business Organizations Law Commons, and the Contracts Commons

\section{Recommended Citation}

David I. Walker, The Way We Pay Now: Understanding and Evaluating Performance-Based Executive Pay, in No. 15-34 Boston University School of Law, Law and Economics Research Paper (2015).

Available at: https://scholarship.law.bu.edu/faculty_scholarship/372

This Article is brought to you for free and open access by Scholarly Commons at Boston University School of Law. It has been accepted for inclusion in Faculty Scholarship by an authorized administrator of Scholarly Commons at Boston University School of Law. For more information, please contact lawlessa@bu.edu. 


\title{
BU School of Law
}

\section{The Way We Pay Now: Understanding and Evaluating Performance-BASEd EXECUTIVE PAY}

\author{
Boston University School of Law \\ Law \& Economics Working Paper No. 15-34 \\ Updated October 1, 2015 \\ David I. Walker \\ Boston University School of Law
}

This paper can be downloaded without charge at:

http://www.bu.edu/law/faculty/scholarship/workingpapers/2015.html 


\title{
THE WAY WE PAY NOW: UNDERSTANDING AND EVALUATING PERFORMANCE-BASED EXECUTIVE PAY
}

\author{
David I. Walker*
}

\begin{abstract}
Over the last ten years, performance-based equity pay, and particularly performance shares, has displaced stock options as the primary instrument for compensating executives of large, public companies in the U.S. This article examines that transformation, analyzing the structure and incentive properties of these newly important instruments and evaluating the benefits and risks from an investor's perspective. Notable observations include the following: Although technically "stock" instruments, performance shares mimic the incentive characteristics of options. But performance shares avoid the tax, accounting, and other constraints that have led to uniform grants of non-indexed, at-the-money options. Performance share plans can be designed to be effectively in, at, or out of the money and these plans often employ relative performance measurement that makes them analogous to rarely observed indexed stock options. But the opacity of performance share plans creates risks for investors, and the two accounting approaches applicable to these instruments both result in systematic undervaluation for executive pay disclosure and financial reporting purposes. Given the growing dominance of these instruments, this article advocates the adoption of a mark-to-market accounting regime for all equity compensation.
\end{abstract}

\footnotetext{
* Professor of Law and Maurice Poch Faculty Research Scholar, Boston University School of Law. Acknowledgments to follow.
} 


\section{Table of Contents}

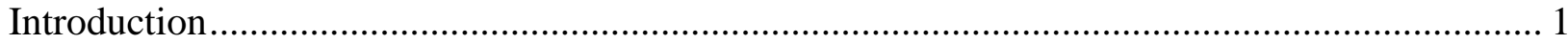

I. A Primer on the Law and Economics of Executive Equity Compensation ............................ 4

II. The Rise of Performance-Based Executive Compensation.............................................. 11

III. Understanding Performance-Based Executive Compensation .......................................... 14

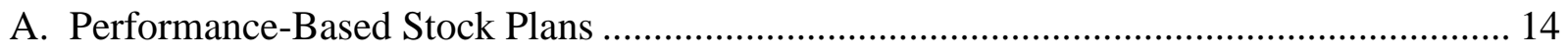

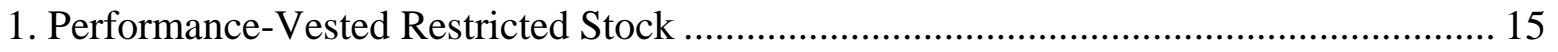

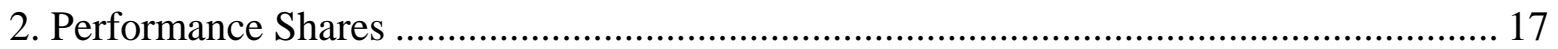

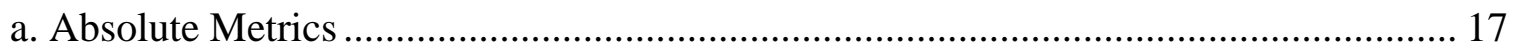

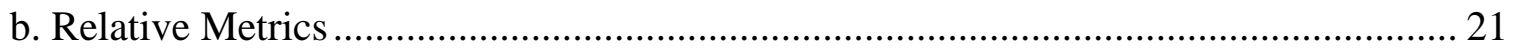

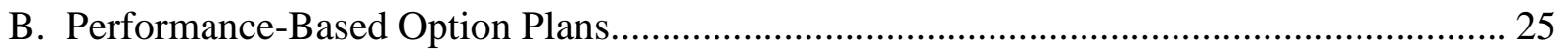

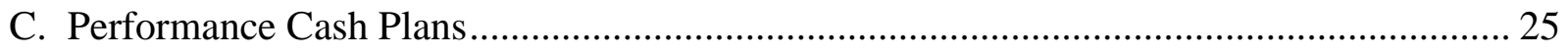

IV. Performance-Based Executive Compensation - An Initial Assessment .............................. 26

A. Advantages of Performance-Based Stock Plans .......................................................... 26

B. Challenges Raised by Performance-Based Equity Pay ................................................. 30

1. Heterogeneity, Complexity, and Related Challenges ................................................ 30

2. Accounting for Compensation Expense Arising from Performance-Based Executive Pay

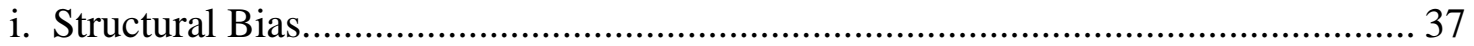

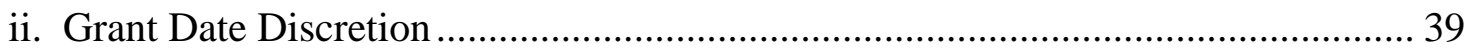

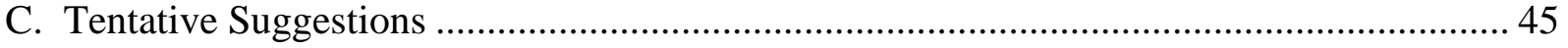

1. Grant Date Valuation and Executive Pay Disclosure ................................................. 45

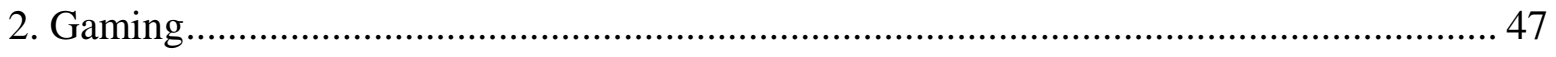

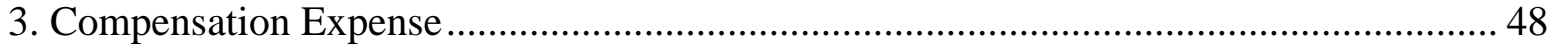

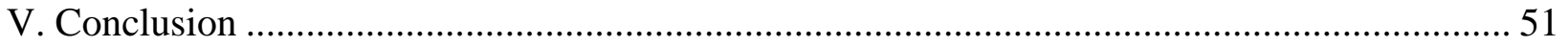




\section{Introduction}

“Stock options are on the verge of extinction.” Wall Street Journal, 8/26/13. ${ }^{1}$

Are executive stock options on the verge of extinction? A cursory look at the data would suggest that many large public companies have abandoned conventional stock options in favor of restricted stock. At the peak of the stock option boom in 2000, options accounted for over 60\% of the total value of compensation awarded to the top executives of a sample of 350 S\&P 500 companies, while restricted stock grants contributed about $10 \% .^{2}$ In 2013 , options accounted for only $17 \%$ of senior executive pay at S\&P 500 companies, while stock grants contributed $42 \%{ }^{3}$

Such a fundamental shift in the composition of equity pay in just a little over a decade would seem to have profound implications for executives, shareholders, and their companies. One commentator has suggested that the shift means more certain returns for executives and simpler compensation, but also the loss of a powerful executive wealth generator and incentive device. ${ }^{4}$ But it isn't clear that any of this is true. First, options remain popular with start-up firms, particularly tech companies. ${ }^{5}$ But even at S\&P 500 firms, there is both more and less than meets the eye in the switch from options to stock. Stock options have not been replaced with traditional restricted stock - stock that "vests" or becomes owned outright with the simple passage of time. Instead, the void has been filled by performance-vested stock, performance shares, and similar "stock" instruments. ${ }^{6}$ A participant in a typical performance share plan receives a variable number of shares after, say, three years, depending on firm performance along any number of accounting or share-value metrics. Under these plans, stronger firm performance generally means both more shares and more valuable shares, producing a multiplier effect that resembles the economics of a stock option. ${ }^{7}$ So, while conventional options may be on the way out, option-like leverage remains vibrant.

But this shift isn't just an example of old wine in new bottles. There are significant differences between traditional stock options and performance-based stock that have important implications for participants, shareholders, and regulators. On the positive side, performance share and performance-vested stock plans often employ relative performance metrics. ${ }^{8}$ The number of shares awarded is a function of a company's stock returns, earnings, or revenue relative to the returns, earnings, or revenue at a peer group of companies. As a result, these

\footnotetext{
${ }^{1}$ Emily Chasan, Last Gasp for Stock Options?, CFO Journal Blog, The Wall Street Journal.

${ }^{2}$ David I. Walker, Evolving Equity Compensation and the Limits of Optimal Contracting, 64 Vand. L. Rev. 611, 633 (2011) (reporting data based on grant date valuation).

${ }^{3}$ Author's calculation based on ExecuComp data.

${ }^{4}$ Chasan, supra note $\mathrm{x}$.

${ }^{5}$ Pui-Wing Tam, Stock Options Still Popular with Tech Firms, The Valley, Wall Street Journal, Mar. 4, 2010, at A13C.

${ }^{6}$ Infra.

${ }^{7}$ Infra.

${ }^{8}$ Infra.
} 
instruments are much more responsive to firm-specific performance, answering the longstanding objection that traditional options were simply "pay for pulse" that rewarded executives for general market rises. ${ }^{9}$ In fact, the economics of these instruments closely resembles that of indexed stock options ${ }^{10}$ - a semi-mythical pay device that has been touted for years as the answer to the pay for pulse problem but was rarely adopted, perhaps because of accounting and tax constraints. Performance-based stock designs avoid those constraints. ${ }^{11}$

But from a shareholder advocacy perspective, there are downsides to performance-based stock plans as well. Many of these plans are highly complex. Some involve multiple performance metrics. ${ }^{12}$ It may be relatively simple to determine the number of shares that should be awarded at the end of the performance period, but it is very difficult to gauge the value transferred from company to executive at the time of grant. The Financial Accounting Standards Board (FASB), the accounting standard setter, thinks that we currently lack the technology to determine the ex ante value of many of these instruments. ${ }^{13}$ Given that, how are conscientious directors supposed to gauge the trade-offs between performance shares and options, and between the various potential performance metrics? Moreover, unlike traditional stock options, which tend to follow a one size fits all design, there is great variation in performance share plan metrics and design. While increased customization may be efficiency enhancing, it makes it more difficult for directors, shareholders, and even executives to compare plans from firm to firm. A cynic might suspect that the shift to performance shares is just one more example of boards and executives working together to obfuscate executive pay awards in order to lessen outrage over the ever-increasing amounts transferred to senior management.

In addition, performance-based stock plans are both less and more "gameable" than options. These plans universally gauge performance over a pre-determined period. Unlike options, they do not allow participants to time exercise to their advantage. ${ }^{14}$ That's an improvement. But complex performance metrics are gameable in the choice of peer group, when relative performance metrics are employed, and in the particular metrics selected, e.g., earnings, sales, cash flow, or shareholder return. The chosen metric may perfectly align executive incentives with firm objectives, or the choice might reflect executives' private forecasts based on inside information. ${ }^{15}$

\footnotetext{
${ }^{9}$ E.g., Sudhakar V. Balachandran, Paying for a Pulse, Forbes.com, 10/15/2008. Joann S. Lublin, Boards Tie CEO Pay More Tightly to Performance; Options Grants May Depend On Meeting Financial Goals; Moving Beyond a 'Pulse', Wall Street Journal, Feb. 21, 2006, at A1.

${ }^{10}$ Unlike traditional employee stock options that have a fixed strike or exercise price, the strike price of an indexed option is adjusted up or down based on increases or decreases in an index, such as the S\&P 500 stock price index. See infra.

${ }^{11}$ Infra.

${ }^{12}$ Infra.

${ }^{13}$ Infra.

${ }^{14}$ Infra.

${ }^{15}$ Infra.
} 
Making matters worse, two different accounting regimes apply to performance-based stock instruments depending on the specific metrics employed, both of which are favorable from the firm/executive perspective in that they tend to reduce reported compensation expense and increase earnings, although the mechanisms differ. ${ }^{16}$ One method, which applies to share price or market-based performance hurdles, requires the use of complex models to estimate a grant date fair value, providing firms with significant discretion to select assumptions that will minimize reported compensation. The other method, applicable to accounting-based performance measures, results in a structural downward bias with respect to the expected expense amount and also provides discretion to under-report executive pay as of the grant date. Moreover, both methods are used when both types of performance measures are employed with respect to a single pay award, multiplying the opportunity to under-report executive pay. Although these plans are relatively new, firms are increasingly adopting multiple metrics. We've seen this film before. Just as the highly favorable option accounting rules of the 1990s contributed to that boom, favorable accounting for certain performance share plans already appears to be skewing firm choices in this new era. ${ }^{17}$

Can these drawbacks be addressed while preserving the relative performance measurement benefits of performance-based stock? Perhaps. Our experience with options may provide a useful model. It took many years to develop financial reporting rules that leveled the playing field between various equity instruments and disclosure requirements that would allow investors to evaluate and confirm the company-reported valuation of option grants. Unfortunately, the level playing field for equity pay accounting lasted less than a decade. ${ }^{18}$ At a minimum, the rules need to be revised to eliminate the discrepancies between various new equity pay instruments. More fundamentally, it may be time to stop relying on ex ante valuation of equity pay for accounting purposes and adopt a mark-to-market approach in determining the annual expense to be associated with all of these instruments. This step would not prevent opportunistic mis-valuation of these instruments, but it would reduce the incentive to engage in that behavior.

In addition, much more disclosure of the assumptions used in valuing new equity grants is required. Going further, we might also require disclosure of all of the details and results of the simulations used to value these instruments. Peer group choice must be fully justified and broader groups (e.g., the S\&P 500) might be preferred or mandated to reduce gaming. Firms should be required to justify performance metrics and, in particular, changes in performance metrics, which might be opportunistic. ${ }^{19}$

The remainder of this article is organized as follows. Part I provides a primer on the law and economics of equity compensation, focusing on the incentive-generating properties of

\footnotetext{
16 Infra.

17 Infra.

18 Infra.

${ }^{19}$ Infra.
} 
conventional stock and option grants, relative performance evaluation, and tax and accounting constraints. Part II describes and offers potential explanations for the dramatic shift in executive pay practices over the last decade. Part III analyzes performance-based equity pay, focusing on the now-dominant performance-based stock category, dissecting examples of the most commonly encountered variants, and relating these to conventional equity pay instruments. Although performance-based stock plans now account for the largest single slice of aggregate senior executive pay at S\&P 500 firms, performance-based option grants and long-term cashbased performance plans are observed as well, and are briefly considered. Part IV provides an assessment, evaluating the advantages and disadvantages of performance-based stock as an executive pay instrument. Particular attention is paid in this Part to disparities in accounting and disclosure rules that already appear to be influencing compensation design and to a proposed solution - mark-to-market accounting for all equity compensation.

\section{A Primer on the Law and Economics of Executive Equity Compensation}

This Part sets the stage for our consideration of performance-based stock compensation by reviewing the terms and economics of conventional stock and option pay, as well as the tax and accounting rules that play such an important role in executive pay design.

Equity-based compensation has dominated the pay packages of senior corporate executives since the mid-1990s. ${ }^{20}$ A principal reason firms use equity pay is to create incentives that will mitigate managerial agency costs. Agency costs arise from the separation of ownership and control that characterizes large, public corporations. ${ }^{21}$ These costs reflect the divergence between managerial actions and decisions that would maximize shareholder value and actual actions and decisions, plus monitoring and other costs undertaken to minimize that divergence. ${ }^{22}$ These agency costs are not totally avoidable, but they can be reduced by designing compensation to better align executives’ economic interests with shareholder interests. Long-term, equitybased compensation plays a clear role in that effort. ${ }^{23}$

Conventional stock options, and to a lesser extent restricted stock, reigned supreme during the early years of the equity pay era. These stock and option instruments were highly uniform. Options almost always provided the holder with the right to purchase shares at a future date by paying an amount equal to the market price of the stock on the date of grant, an instrument known as an at-the-money option. ${ }^{24}$ Restricted stock was even simpler. Classically,

\footnotetext{
${ }^{20}$ Walker, supra (Vandy).

${ }^{21}$ Michael C. Jensen \& William H. Meckling, Theory of the Firm: Managerial Behavior, Agency Costs and Ownership Structure, 3 J. FIN. ECON. 305 (1976).

${ }^{22}$ Id.

${ }^{23}$ Walker, supra (Vandy).

${ }^{24}$ Kevin J. Murphy, Executive Compensation, in Orley Ashenfelter and David Card, eds, Handbook of Labor Economics 2458 (1999). Typically, these options would first become exercisable, or "vest", within three or four years of grant and would be exercisable at the discretion of the holder for up to ten years following grant. These options were not transferable.
} 
a firm would award a tranche of shares to an executive on a given date. The shares would be subject to forfeiture if employment terminated before the shares vested and became owned outright. That vesting might occur on one date in the future or a fraction might vest annually for a number of years. Over time, the award of restricted stock units has largely supplanted actual grants of restricted stock. ${ }^{25}$ Instead of issuing stock at grant, firms issuing restricted stock units promise to deliver stock when the shares vest. Although there may be differences in the treatment of dividends and voting rights, ${ }^{26}$ restricted stock and restricted stock units are essentially identical economically, and the term "restricted stock" will be used to refer to both. ${ }^{27}$

Both stock and options tie pay to stock price performance. Stock does so in a linear fashion. Assuming that the shares ultimately vest, a dollar increase in share price translates into an additional dollar of wealth for the holder of a restricted share. ${ }^{28}$

The intrinsic value of an option - the value that would be realized if the option were exercised immediately - follows the "hockey stick" pattern displayed in the figure below. As long as the stock price is less than the exercise price, the option has zero intrinsic value. To the extent that the stock price exceeds the strike price, the option has positive intrinsic value equal to the difference. But prior to expiration, an option's total value exceeds its intrinsic value because the stock price may rise, increasing the payout on the option. The full value of an unexercised option also increases and decreases with increases and decreases in the share price, but the relationship is not linear, it is convex. ${ }^{29}$ An option that is far out of the money, i.e., with strike price far in excess of the current value of the underlying shares, has a low value and a value that is relatively insensitive to the value of the underlying shares. The value of an option that is far in the money, i.e., with strike price far below the current value of the underlying shares, approaches the current share price less the exercise price, and that value moves dollar for dollar with small changes in the underlying share price. The relationship is plotted in the figure below. ${ }^{30}$

\footnotetext{
${ }^{25}$ Hay Group, the Executive Edition, Sept. 2013.

${ }^{26}$ Hay Group, the Executive Edition, Sept. 2013.

${ }^{27}$ Another difference is that IRC section 83(b) elections can be made for restricted stock grants but not for grants of restricted stock units (RSUs). An 83(b) election results in taxation of the recipient based on the grant date value of the award rather than the realized value on vesting. But there are significant downsides to 83(b) elections and they are rarely observed in the public company context, so this difference is of little real consequence. Myron S. Scholes et al., Taxes and Business Strategy: A Planning Approach 221 (5th ed. 2014). See Robert L. McDonald, Is It Optimal to Accelerate the Payment of Incomes Tax on Share-Based Compensation? Section 2.3 (Working Paper, Sept. 19, 2003), available at http://www.kellogg.northwestern.edu/faculty/mcdonald/htm/opexer.pdf.

${ }^{28}$ Walker, supra (Vandy).

${ }^{29}$ Walker, supra (Vandy). When graphed, a convex relationship presents a U-shaped curve. The relationship between option value and the price of the underlying shares tracks the right half of the $U$.

${ }^{30}$ In the figure, the asset "spot" price refers to the current market price of the stock.
} 


\section{Value before expiration at time $t$}

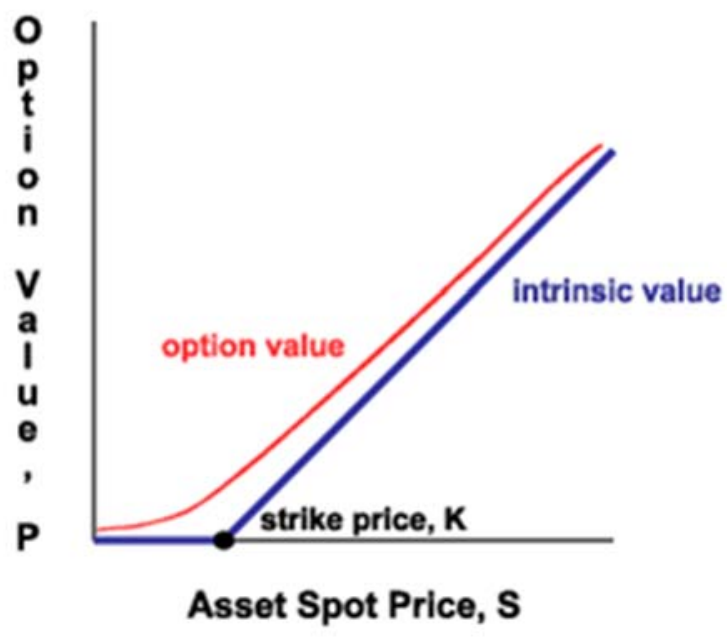

Economists use the term "delta" to describe the change in the value of an instrument arising from a small change in the underlying share price. Restricted stock has a delta equal to 1.0. Options have a delta of less than 1.0. ${ }^{31}$ Per share, options provide less of an incentive to increase the share price than does stock. However, options are also cheaper to grant than stock. Remember that conventional restricted stock vests with the simple passage of time. As long as an executive remains employed, she is certain to receive something of value - more or less value depending on the share price - but something of value nonetheless. Not so with an option. The option may expire unexercised out of the money. Thus, the expected cost of providing an option is much less than that of issuing stock. When these two effects are combined, it turns out that per dollar of compensation expense, options produce stronger incentives than restricted stock more delta per dollar. ${ }^{32}$

In addition to increasing the sensitivity of pay to share price performance, replacing stock compensation with equally valuable option compensation increases the sensitivity of pay to the volatility of share prices. Economists use the term "vega" to denote the sensitivity of option value to volatility. ${ }^{33}$ The value of shares is not directly affected by changes in volatility, and thus restricted stock has vega of zero. The value of an option, on the other hand, increases with increasing volatility of the underlying share price. Options have positive vega. Thus, adding options to a compensation package tends to increase an executive's appetite for volatility, which means increasing the appetite for taking on risky projects. If one believes that executives tend to

\footnotetext{
${ }^{31}$ An option that is far in the money and is almost certain to be exercised has a delta that approaches 1.0. Options that are at the money or somewhat in or out of the money have a delta of less than 1.0. See JoHn C. Hull, Options, FUTURES, AND OTHER DERIVATIVES 251 (6th ed. 2006) (explaining the concept of the option delta).

${ }^{32}$ Walker, supra (Vandy).

${ }^{33}$ Hull, supra.
} 


\section{The Way We Pay Now}

be excessively risk averse because they have so much of their financial and human capital tied up in their firms, option pay can mitigate this agency problem. ${ }^{34}$ This is the classic corporate finance story for the adoption of option-based pay.

Although options are uniformly granted at the money, this is not inevitable; nor is it clearly optimal. Pay packages provide compensation and incentives. Directors want to provide high-powered incentives to encourage executives to work hard and to take on risky projects, but pay packages must be mutually acceptable, and executives - who cannot easily diversify - apply large discounts to very risky pay. It is costly, in other words, for shareholders to impose high delta and high vega pay packages on executives. ${ }^{35}$

Restricted stock, which in economic terms is an option with an exercise price of zero, is the safest form of conventional equity pay from the point of view of the executive. At-themoney options are generally risky. In-the-money options with a positive exercise price fall in between stock and at-the-money options on this spectrum. Out-of-the-money options are even riskier. ${ }^{36}$ Ideally firms would select the "moneyness" of their equity pay packages to optimize compensation and incentives, to balance executive risk aversion against the value of creating high-powered incentives.

Corporate finance researchers have studied the design of equity pay extensively and have concluded that the optimal arrangement ranges from far in-the-money options (i.e., restricted stock) to far out of the money options, depending on firm and executive characteristics. ${ }^{37}$ However, many studies have concluded that within a certain range of assumptions, in-the-money options would be optimal. ${ }^{38}$ So why are conventional options uniformly granted at the money? Tax and accounting rules play a leading role, as will be discussed below.

\footnotetext{
34 See Brian J. Hall, Six Challenges in Designing Equity-Based Pay, 15 J. ApPLIED CoRP. FIN. 21, 29 (2003) (explaining the risk aversion of under-diversified executives). Shareholders, by comparison, are assumed to be diversified and risk neutral.

35 See Brian J. Hall \& Kevin J. Murphy, Stock Options for Undiversified Executives, 33 J. AcCT. \& ECON. 3 , 5 (2002) (explaining that "[r]estricting the trading and hedging activities of option recipients" causes executives receiving the options to "value the options below their cost to shareholders"); see also John E. Core et al., Executive Equity Compensation and Incentives: A Survey, ECON. PoL’y REV., Apr. 2003, at 27, 30 (noting that equity compensation is risky because stock prices are a noisy measure of firm performance and that recipients must be compensated for taking on the non-diversifiable risk).

${ }^{36}$ One way to think about this is to consider the odds of an option expiring out of the money. Restricted stock cannot expire out of the money. An option that is in the money at grant is less likely to expire out of the money than an option that is at the money at grant. Etc.

${ }^{37}$ Compare Hall \& Murphy, supra note x, at 26-27 (concluding that "when existing compensation is adjusted, incentives are maximized through restricted stock grants rather than options”) with Richard A. Lambert \& David F. Larcker, Stock Options, Restricted Stock, and Incentives 2 (2004) (unpublished manuscript), available at http://papers.ssrn.com/sol3/papers.cfm?abstract_id=527822 ("exercise price in the optimal contract is frequently far 'out of the money' ").

${ }^{38}$ See Yisong S. Tian, Too Much of a Good Incentive? The Case of Executive Stock Options, 28 J. BANKING \& FIN. 1255, 1227 (2004) ("incentive-maximizing exercise price is typically greater than zero but less than the stock price”); Oded Palmon et al., Optimal Strike Prices of Stock Options for Effort-Averse Executives, 32 J. BANKING \& FIN. 229, 230-31 (2008) (simulations suggest that options are optimally granted in the money); Yisong S. Tian,
} 
Conventional options are uniformly granted with a fixed exercise price. This is another initially puzzling uniformity since corporate finance theorists predict that firms would employ relative performance evaluation (RPE) to improve the efficiency of incentive contracts, ${ }^{39}$ and fixing the exercise price of an option foregoes an opportunity to introduce RPE into the scheme. Stock prices (and option values) rise and fall depending on the performance of a specific firm but also on the performance of the firm's sector or the overall market. Executives have no control over the overall market; little control over the performance of their peers; and the most control over the performance of their firm. The idea behind RPE is to tie compensation as closely as possible to performance outcomes within the control of the executive and eliminate risks over which executives have no control. In the case of stock options, RPE would be explicitly implemented by adjusting the exercise prices of options for increases or decreases in the average share price of a peer group of companies or of the overall market. This is known as an indexed option. ${ }^{40}$ Since shareholders must compensate executives for taking on un-controllable risks, adopting more efficient, indexed option contracts should ultimately redound to the benefit of shareholders. $^{41}$

More prosaically, there are two obvious advantages to indexing stock options. First, indexation eliminates the possibility of executive windfalls that arise when compensation consists of traditional options and the overall market rises, lifting all boats. It is very hard to look at the stock market run up in the 1990s and not conclude that many executives holding options reaped unearned gains. Second, indexation also mitigates the risk that a market downturn will unfairly penalize high-performing executives holding conventional options and that conventional options will move far out of the money in this scenario and cease providing effective incentives.

Absent regulatory constraints, firms might attempt to design equity pay packages to minimize agency costs as suggested above. I say might, because another school of thought posits that maximizing shareholder value is not the sole objective of this process. ${ }^{42}$ But even those who adhere strongly to the "optimal contracting" view of the executive pay setting process

Optimal Contracting, Incentive Effects and the Valuation of Executive Stock Options (Working Paper, Apr. 30, 2001) at 32 (arguing that the optimal option design ranges from at the money to deep in the money, i.e., restricted stock, depending on degree of risk aversion).

${ }^{39}$ Bengt R. Holmstrom, Moral Hazard in Teams, 13 Bell J. Econ. 324 (1982).

${ }^{40}$ See Alfred Rappaport, New Thinking on How to Link Executive Pay with Performance, HaRv. Bus. Rev. 91, 101 (Mar. - Apr. 1999).

${ }^{41}$ But see Ingolf Dittmann et al, Indexing Executive Compensation Contracts, 26 REV. FIN. STUDIES (2013) (arguing that indexation reduces option delta requiring firms to issue more indexed options to maintain incentives and that the tradeoff is generally suboptimal); Pierre Chaigneau et al, The Value of Informativeness for Contracting (working paper 2015) (showing that indexation reduces incentives).

${ }^{42}$ See Lucian A. Bebchuk, Jesse M. Fried \& David I. Walker, Managerial Power and Rent Extraction in the Design of Executive Compensation, 69 U. CHI. L. REV. 751 (2002) (hereinafter BFW) (proposing a managerial power theory of the executive pay setting process). 
recognize that tax and accounting rules strongly influence and sometimes limit what can be achieved. $^{43}$

It seems unlikely that the failure to index options was a result of obscurity. The idea was repeatedly floated in the 1990s. Alfred Rappaport promoted the concept in a Harvard Business Review article in $1999 .{ }^{44}$ And a few firms, such as Level 3 Communications, experimented with indexed options and received significant attention in the press. ${ }^{45}$ But the idea never caught on.

So, we have two puzzles. Why are all options granted at the money and why didn't firms index exercise prices? Accounting and tax rules, I believe, figure prominently in the answer.

Through 2005, U.S. accounting rules strongly favored the issuance of conventional, fixed exercise price, non-discounted (i.e., at- or out-of-the-money) options over other forms of equity pay, such as restricted stock. A grant of restricted stock resulted in firms booking an expense over time for compensation cost equal to the market value of the stock at the time of grant, but no expense was recorded for fixed exercise price, non-discounted options at the time of grant, vesting, or exercise. ${ }^{46}$ These options were "free" from an accounting perspective. (Indexed options, by contrast, were subject to a relatively onerous "mark-to-market" accounting regime under the pre-2006 accounting rules. ${ }^{47}$ ) Kevin Murphy has argued that the popularity of conventional at-the-money options in the late 1990s and early 2000s reflected the mis-perceived cost of these options arising from their highly favorable accounting treatment. ${ }^{48}$

In 2004, the Financial Accounting Standards Board (FASB) issued a new standard requiring firms to determine the grant date fair value of all equity compensation and to recognize this cost as an expense over the vesting period of the stock or option. ${ }^{49}$ This shift leveled the accounting playing field for stock and conventional options, and in all likelihood contributed to

\footnotetext{
${ }^{43}$ E.g., Murphy, supra (1999) (suggesting stock option boom resulted from misperceived low cost of option pay resulting from former accounting regime).

${ }^{44}$ Rappaport, supra note $\mathrm{x}$, at 101; see also Mark A. Clawson \& Thomas C. Klein, Indexed Stock Options: A Proposal for Compensation Commensurate with Performance, 3 Stan. J. L. Bus. \& Fin. 31, 31-50 (1997).

${ }^{45}$ E.g., Joann S. Lublin, Pay for Outperforming: James Crowe, Chief of Level 3 Communications, Makes the Case for Linking Stock Options to Market-Beating Gains, Wall St. J. R8 (Apr. 6, 2000) (reporting on Level 3 Communication's use of S\&P 500 indexed options).

${ }^{46}$ See AcCt. Principles Bd., Opinion No. 25, AcCounting for Stock Issued to EMployees (1972) [hereinafter APB 25]. Under APB 25, only the intrinsic value of an option - the degree to which an option was in the money at the date of grant was recognized as an expense.

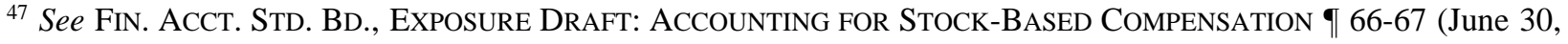
1993). The pre-2006 rules also required performance shares, discussed in the next Part, to be marked to market.

${ }^{48}$ His argument is that managers and directors mis-perceived the cost of this form of compensation as a result of the artificially favorable accounting treatment. Kevin J. Murphy, Executive Compensation: Where We are, and How We Got There 80 (2012), available at (http://papers.ssrn.com/abstract=2041679) ("The accounting treatment of options promulgated the mistaken belief that options could be granted without any cost to the company. . . . Nonetheless, the idea that options were free (or at least cheap) was erroneously accepted in too many boardrooms").

49 See Fin. Acct. StD. Bd., Statement of Financial Accounting Standards No. 123 (Revised 2004) [henceforth SFAS 123R].
} 
the movement away from conventional options in the 2000s. Now that they were no longer "free," firms were less inclined to issue options. ${ }^{50}$

Federal income tax rules have played at least a supporting role in this story. Internal Revenue Code (IRC) $\S 162(\mathrm{~m})$, enacted in 1993, limits the deductibility of non-performance based compensation issued to certain senior executives to $\$ 1$ million per year. Although firms increasingly treat this $\$ 1$ million "cap" as simply a consideration, and not a limitation on nonperformance based pay, the enactment of 162(m) likely contributed to the shift in favor of options in the early 1990s. While conventional options easily qualify as performance-based pay, salary (and time-vested restricted stock) does not. ${ }^{51}$

Today, a tax rule enacted in 2004 - IRC § 409A - essentially precludes the issuance of in-the-money or indexed exercise price options. Under regular U.S. tax rules, compensation arising from a conventional, non-discounted option is not taxed until the option is exercised. ${ }^{52}$ However, under $\S 409 \mathrm{~A}$, compensation arising from a discounted or indexed option would be taxed at vesting, rather than at exercise, and would be subjected to an additional $20 \%$ penalty $\operatorname{tax}^{53}$

Fixed exercise price, out-of-money options are feasible, but are rarely seen, presumably because recipients excessively discount these options. Recipients would tend to focus excessively on their out-of-the-money-ness. ${ }^{54}$ Given $\S 409 \mathrm{~A}$ and this behavioral effect, it is no surprise that $99+\%$ of options are issued with a fixed exercise price that is at the money.

Of course, it is also possible that the failure to index options is consistent with optimal contracting. Despite the contracting advantages of RPE identified by Holmstrom, option indexation has been shown to reduce incentives, and it is possible that the tradeoff simply isn't

\footnotetext{
${ }^{50}$ Kevin J. Murphy, Executive Compensation: Where We Are, and How We Got There 97 (2012), available at (http://papers.ssrn.com/abstract=2041679).

${ }^{51}$ Treas. Reg. § 1.162-27(e)(2)(vi) (providing that stock options will be deemed to be performance based if granted by the firm's compensation committee in accordance with a plan meeting certain minimal requirements). David Schizer concludes that while indexed options can qualify as performance based pay under IRC §162(m), the path to qualification is more cumbersome. See David M. Schizer, Tax and Corporate Governance: The Influence of Tax on Managerial Agency Costs 10 (working paper, Sept. 19, 2014).

${ }^{52}$ I assume in this discussion that options are non-qualified options, i.e., not incentive stock options (ISOs) as defined in IRC 422. The tax rules applicable to ISOs differ, but ISOs account for an economically trivial portion of executive equity pay.

${ }^{53}$ These option designs fall outside of a safe harbor within §409A. As a result, they are treated like other deferred compensation, and under § 409A participant control over the timing of realization of deferred compensation results in penalties. See infra note $x$ and accompanying text. In addition, indexed options and options granted in the money do not qualify for the safe harbor presumption of performance based pay applicable to at the money options. See Treas. Reg. $\S 1.162-27(\mathrm{e})(2)(v i)$ (stock options deemed to satisfy the safe harbor presumption if, inter alia, "the amount of compensation the employee could receive is based solely on an increase in the value of the stock after the date of the grant").

${ }^{54}$ See Brian J. Hall, The Pay to Performance Incentives of Executive Stock Options 32 (Nat'l Bureau of Econ. Research, Working Paper No. 6674, 1998), available at http://papers.ssrn.com/sol3/papers.cfm?abstract_id=108563 (finding a "bias toward valuing options according [to] what they would be worth if exercised today").
} 
worth it. ${ }^{55}$ However, as we will see shortly, firms have embraced RPE in performance share plans that are economically similar to options, but do not suffer the same adverse tax consequences, suggesting that tax and accounting rules are the better explanations.

\section{The Rise of Performance-Based Executive Compensation}

According to the Hay Group, 27.4\% of the ex ante value of compensation paid to the CEO's of 300 of the largest U.S. companies in 2012 consisted of performance-based equity pay, that is, performance-based stock or options. ${ }^{56}$ A very large fraction of this pay would have consisted of performance-based stock. The same Hay Group study found that $78 \%$ of these 300 firms issued performance-based stock to their top executives in 2012, while only 5\% issued performance-based options to this group. (16.0\% of the firms made awards to top executives under cash-based long-term performance plans.) ${ }^{57}$ Similarly, analyzing the compensation of top executives of over 1000 large public companies, Bettis, Bizjak, Coles, and Kalpathy (BBCK) found that $97 \%$ of the firms that utilized performance-based equity pay issued performancebased stock, while only $8 \%$ issued performance-based options. ${ }^{58}$

Performance-based equity pay existed a decade ago, but was much less frequently observed. BBCK's data indicate that the fraction of equity pay consisting of performance-based pay has increased by $350 \%$ from $2001 .^{59}$

Meanwhile, use of the once ubiquitous conventional at-the-money stock option continues to decline. These options accounted for only $16.4 \%$ of CEO pay for the Hay Group sample of firms in 2012. ${ }^{60}$ At the peak of the option boom around 2000, conventional options accounted for over $60 \%$ of senior executive pay. ${ }^{61}$ Rounding out the picture, use of conventional timevested restricted stock has increased modestly over the decade, and, with a 13.2\% market share of CEO compensation for the Hay Group sample in 2012, conventional restricted stock may be overtaking conventional options for second position among equity pay categories. ${ }^{62}$

Of course, the top 300 and even the top 1000 firms are only a subset of U.S. public companies. Nonetheless, pay practices at these firms deserve close attention because they tend

\footnotetext{
55 See Dittmann et al, supra note $\mathrm{x}$; Chaigneau et al, supra note $\mathrm{x}$.

${ }^{56}$ Hay Group, Executive Compensation 2013: Data, Trends and Strategies 19 (2014).

${ }^{57}$ Hay Group (2014) at 20, 21.

58 J. Carr Bettis, John Bizjak, Jeffrey Coles \& Swaminathan Kalpathy, Performance-Vesting Provisions in Executive Compensation, Table 1 (working paper, Dec. 18, 2013) (hereinafter BBCK (2013)). BBCK's sample was based on the largest 750 companies each year between 1998 and 2012 for a total of 1833 firms. Roughly 1100 to 1400 firms are represented each year.

${ }^{59}$ BBCK (2013) at Table 1. This figure actually understates the transformation. Performance-accelerated stock and option grants made up a sizable portion of performance-based equity pay in 2001, and a negligible fraction in 2012. As discussed below, performance-accelerated equity is a closer kin to conventional stock and option pay than it is to today's performance shares and performance-vested options.

${ }^{60}$ Hay Group (2014) at 19.

${ }^{61}$ Walker, supra (Vandy) at 633.

${ }^{62}$ Hay Group (2014) at 19, 22 (making this prediction).
} 
to be leaders in the adoption of executive pay practices and because they make up such a large fraction of U.S. market capitalization. ${ }^{63}$ For the average investor, these are the firms that matter most from a governance perspective.

Explaining the shift from options to performance shares really involves two questions: why the shift away from options, and why the shift to performance shares? In hindsight, the heavy reliance on options in the late 1990s/early 2000s looks like a bubble induced by the artificially favorable accounting treatment of option compensation that was discussed above. ${ }^{64}$ Recall that prior to a change in accounting standards adopted in 2004, firms incurred no charge to earnings at any point for conventional at-the-money options issued to executives and employees as compensation. All other forms of compensation, including restricted stock, resulted in an accounting expense. In 2004, the FASB mandated "fair value" accounting for all forms of equity compensation, leveling the accounting playing field for stock and options. ${ }^{65}$ According to this view, once the thumb on the scale in favor of options was removed, options looked relatively less attractive and their use declined. ${ }^{66}$

Other factors may have contributed to the shift away from options. ${ }^{67}$ The bursting of the dot-com bubble around 2000 and the end of "irrational exuberance"68 likely led to an increase in the perceived riskiness of options on the part of executives, reducing their attractiveness. ${ }^{69}$ Options-related scandals at Enron, WorldCom, Tyco and other firms in the early 2000s, as well as a stock option backdating scandal in the mid-2000s, all made "options" something of a four letter word in the minds of the media, investors, and the general public. ${ }^{70}$ A tax cut on dividends in 2003 increased the attractiveness of dividends. ${ }^{71}$ Because their options are rarely "dividend protected", executives holding options are thought to be averse to paying dividends. Investors anticipating this antipathy might have pushed for fewer options in executive pay packages. ${ }^{72}$

\footnotetext{
${ }^{63}$ The S\&P 500 represents $80 \%$ of US stock market capitalization. S\&P Dow Jones Indices, Market Capitalization Coverage of S\&P U.S. Equities, http://us.spindices.com/documents/additional-material/sp-500-trifold.pdf (last visited Aug. 19, 2015).

${ }^{64}$ Walker, supra (Vandy); Murphy supra.

${ }^{65}$ SFAS 123R, supra.

${ }^{66}$ Murphy, supra.

${ }^{67}$ Walker (Vandy) (discussing potential explanations for the shift away from conventional options).

${ }^{68}$ Alan Greenspan, 1996.

${ }^{69}$ Walker, supra (Vandy).

${ }^{70}$ Walker, supra (Vandy).

${ }^{71}$ The Jobs and Growth Tax Relief Reconciliation Act of 2003 cut the top marginal federal income tax rate applicable to dividends from thirty-five percent to fifteen percent. For evidence on the impact on dividend payouts, see Jeffrey R. Brown et al., Executive Financial Incentives and Payout Policy: Firm Responses to the 2003 Dividend Tax Cut, 62 J. Fin. 1935, 1935 (2007) (reporting that thirty-five percent of S\&P 1500 firms increased dividend payouts in 2003 compared with twenty-seven percent increasing payouts in the two prior years and that the rate of firms newly adopting dividend programs increased from about one in a hundred in 2001 and 2002 to one in ten in 2003).

${ }^{72}$ Walker, supra (Vandy).
} 
The foregoing factors, and others, ${ }^{73}$ might help explain a shift away from options and in favor of stock, but why the heavy shift into performance-based stock? Why not conventional time-vested restricted stock? We can't be certain, but conventional time-vested restricted stock has several drawbacks as an equity pay instrument. First, conventional time-vested restricted stock does not qualify as performance-based pay under $\S 162(\mathrm{~m})$ of the tax code. ${ }^{74}$ In a world in which the median S\&P 500 CEO receives annual compensation of over \$10 million, the \$1 million senior executive pay deduction limitation under $\S 162(\mathrm{~m})$ and the performance-based pay exception are important. ${ }^{75}$ By contrast, performance-based stock plans can easily qualify as fully deductible performance-based pay. ${ }^{76}$

Second, the increasingly influential proxy advisory firms - Institutional Shareholder Services and Glass Lewis - do not consider time-vested restricted stock to be performance-based pay. These firms tend to give negative recommendations on "say on pay" proposals when companies include significant levels of time-vested restricted stock in their proposed pay packages. $^{77}$

Third, and relatedly, boards may not believe that simple time-vested restricted stock provides the optimal incentives for executives. We have seen that both stock and options tie pay to stock price performance, but that options, per dollar of compensation expense, provide more highly powered incentives than stock - incentives to increase the share price and incentives to take on risky projects. ${ }^{78}$ Of course, option pay can potentially lead to an excessive appetite for risk. Some commentators have blamed heavy executive option portfolios for the excesses that led to the 2008 financial crisis. ${ }^{79}$ Nonetheless, it is certainly plausible that some directors would conclude that a wholesale shift from option pay to time-vested restricted stock would excessively discourage risk taking. We will see that performance-based stock has incentive properties that

\footnotetext{
${ }^{73}$ Walker, supra (Vandy).

${ }^{74}$ See Treas. Reg. § 1.162-27(e)(2)(vi) and note x, supra.

75 Equilar, CEO Pay Strategies Report 8 (2014) (reporting median S\&P 500 CEO total compensation for 2013 of $\$ 10.132$ million). The importance of qualifying executive pay as performance based would disappear if legislation proposed by Rep. Lloyd Doggett (D-Tex.), and Senators Jack Reed (D-R.I.) and Richard Blumenthal (D-Conn.) is enacted. Both the House and Senate bills propose to disallow all deductions for exec pay in excess of $\$ 1 \mathrm{~mm}$, regardless of composition. See Equilar, CEO Pay Strategies Report 18 (2014). Donald Kalfen, House Bill Would Extend Reach of $162(\mathrm{~m})$ to All Employees and Eliminate (Significant) Exemption for Performance-Based Compensation, Meridian Client Update, Meridian Compensation Partners, LLC. 1 (Feb. 22, 2014), http://www.meridiancp.com/wp-content/uploads/house-bill-will-eliminate-tax-exemption.pdf. 76 Supra.

77 See Institutional Shareholder Services, United States Taft-Hartley Proxy Voting Guidelines: 2015 Policy Recommendations 30 (Feb. 4, 2015), available at http:/www.issgovernance.com/file/policy/2015-taft-hartleyadvisory-services-us-guidelines.pdf; James F. Reda \& David M. Schmidt, SAY-on-PAY: Changing How Executives Get Paid, 29(7) Financial Executive 24, 27 (Sep. 2013), available at http://papers.ssrn.com/abstract=2376329.

${ }^{78}$ Walker, supra (Vandy).

${ }^{79}$ Lucian Bebchuk, Executive Pay and the Financial Crisis, HARVARD LAW SCHOOL FORUM ON CORPORATE GOVERNANCE \& FINANCIAL REgULATION, http://corpgov.law.harvard.edu/2012/02/01/executive-pay-and-thefinancial-crisis/ (last visited Aug. 22, 2015). See Lucian A. Bebchuk et al., The Wages of Failure: Executive Compensation at Bear Stearns and Lehman 2000-2008, at 1-2 (Nov. 24, 2009), http://papers.ssrn.com/abstract=1513522.
} 
are much closer to options than simple time-vested restricted stock. Firms may have adopted performance-based stock plans to retain the incentive properties of options while abandoning a disfavored instrument.

Finally, and more pessimistically, time-vested restricted stock is a fairly transparent device. Boards and executives who are interesting in obfuscating pay levels might prefer a more opaque instrument, particularly one that can be undervalued through judicious selection of assumptions. ${ }^{80}$ As we will see below, performance-based stock plans are highly complex and opaque. One cannot generate an ex ante value by plugging a few variables into an online calculator, as one can with options. This point will be explored in greater detail in Part X below.

\section{Understanding Performance-Based Executive Compensation}

Performance-based pay is certainly not one size fits all. Both stock and options are being granted to executives contingent on satisfaction of performance conditions. We will look at both types of instruments (as well as cash-based performance plans), but the focus will be on the more common performance-based stock grants. But even with respect to stock grants, there are variations along several dimensions - absolute and relative performance metrics, accounting and market-based hurdles, variable share versus fixed share awards. Thus, it is not possible to provide a complete description that captures the entire range. Nonetheless, this Part describes the major strands that make up the stock award sector of performance-based equity pay.

\section{A. Performance-Based Stock Plans}

Like conventional restricted stock and restricted stock units, performance-based restricted stock can entail the issuance of shares or the equivalent promise to deliver shares at vesting. The innovation here is that the shares vest only if both time and performance criteria are satisfied.

Many different metrics are employed in designing performance-based stock plans, and many plans include more than one metric. According to executive pay consultant F.W. Cook, the most popular metrics for 2013 equity grants at the largest U.S. public companies were (in descending order): total shareholder return, profit (EPS, etc.), capital efficiency (ROE, etc.), revenue, cash flow, and "other", which might include safety or quality measures. ${ }^{81} 45 \%$ of the companies in F.W. Cook's sample used a single performance measure in their plans, with the rest using two or more measures. ${ }^{82}$

\footnotetext{
${ }^{80} \mathrm{BFW}$, supra at 789 (discussing the critical role of camouflage in minimizing investor outrage and increasing executive pay under the managerial power view of the compensation-setting process).

${ }^{81}$ Frederic W. Cook \& Co., Inc., The 2014 Top 250 Report 12 (2014) (hereinafter Cook (2014)). Cook’s sample includes the 250 largest companies in the S\&P 500 index.

${ }^{82}$ Cook (2014) at 13. A recent study by Equilar provides similar data. For 2013, they found that $40 \%$ of S\&P 500 firms that granted long-term performance awards to their CEOs used a single metric; $36 \%$ used two metrics; and the remaining $24 \%$ used three or more metrics. Equilar (2014) at 2-3.
} 
Another major design consideration is whether to base the plan on an absolute measure of performance, a measurement relative to a peer group, or both. In F.W. Cook's sample, a large majority of firms employing a total shareholder return metric used a relative measure, while the large majority of firms using accounting-based metrics employed absolute measures. ${ }^{83}$ In BBCK's sample of top executive pay at large U.S. companies, 82\% of firms issuing performance equity in 2012 employed at least one absolute metric and 48\% employed at least one relative metric. Obviously, many of these companies utilized both. ${ }^{84}$

Finally, the number of shares potentially subject to vesting may be fixed or variable. Following the typical convention, I will use the term "performance-vested restricted stock" to refer to grants of a fixed number of shares or of units entailing the promise to deliver a fixed number of shares upon satisfaction of vesting conditions. I will use the term "performance shares” to refer to performance-based stock plans involving a variable number of shares.

Before turning to performance-vested restricted stock, I should say a word about performance-accelerated restricted stock. Performance-accelerated restricted stock vests after a certain number of years, if the participant remains employed, but the shares can vest earlier if performance goals are achieved. Fifty-two of 1369 firms (4\%) in BBCK's sample issued performance-accelerated restricted stock in 2004, but these instruments have virtually disappeared with only nine firms (less than 1\%) issuing them in $2012 .{ }^{85}$ Given the paucity of these plans, and the fact that their incentive properties are not that different from conventional time-vested restricted stock, we will devote no more attention to them.

\section{Performance-Vested Restricted Stock}

Performance-vested restricted stock refers to grants of a single tranche of shares (or the equivalent promise to deliver the tranche) that vest only if both time and performance hurdles are achieved. For example, in 2013 Medtronic provided its president, Omar Ishrak, with 72,585 restricted stock units which vest on the third anniversary of the date of grant provided that Ishrak remains employed by Medtronic and that the company achieves a cumulative compound annual growth rate in earnings per share of $3 \% .^{86}$ Assuming that Ishrak remains in office, there are two possibilities. If the company achieves the performance goal, Ishrak receives the shares, and the result is equivalent to simple time-vested restricted stock. The value of the grant, ex post, is a linear function of the company's share price at vesting. If the performance goal is not met, Ishrak receives nothing. The performance relationship here is not very nuanced, and unsurprisingly, the proxy materials note that the performance goal for vesting is "intentionally

\footnotetext{
${ }^{83}$ Cook (2014) at 12.

${ }^{84}$ BBCK (2013) at Table 2, Panel E. BBCK's data represent firm years. Some of this overlap could reflect performance equity plans utilizing both absolute and relative measures while some could reflect multiple plans at a given firm, one or more utilizing absolute and one or more utilizing relative metrics. It is impossible to say from the data presented by BBCK.

${ }^{85}$ BBCK (2013) at Table 2, Panel A.

${ }^{86}$ Medtronic, Proxy Statement (Form DEF 14A), at 39, 51, 52 (July 12, 2013).
} 
less than Medtronic's target performance” for growth in EPS. ${ }^{87}$ In other words, this was designed to be an easy hurdle.

While some firms employ easily achievable targets, other firms lessen the potential harshness of an all-or-nothing restricted stock performance hurdle of this sort by extending the period during which the performance goal may be achieved. For example, in 2013 Danaher Corp. granted RSUs to its executives that vest no earlier than the $4^{\text {th }}$ and $5^{\text {th }}$ anniversary of grant (50\% on each anniversary) but that can vest as late as the $10^{\text {th }}$ anniversary of grant. ${ }^{88}$ In order for these RSUs to vest, the company must achieve four consecutive quarters with adjusted EPS in excess of $110 \%$ of 2013 EPS and positive net income. ${ }^{89}$ As before, the value of the grant is a linear function of the share price at vesting, but in this case, vesting may be deferred, if necessary to achieve the performance goal.

While the relationship between share price and actual payoff if the shares vest is linear, the relationship between share price and the expected payoff associated with the performancevested restricted stock issued to Medtronic's Ishrak is non-linear, as illustrated in the figure below. Although the company admits that the performance target is not aggressive, ${ }^{90}$ there is some possibility that it will not be achieved. In all likelihood, Medtronic's share price would suffer as a result. There is, in other words, a positive correlation between the likelihood that the earnings growth target will be met (and that the shares will vest) and Medtronic's share price. For illustration, I am assuming that the likelihood of vesting is zero if Medtronic's share price is zero in three years' time (a safe bet) and that the likelihood increases until it reaches 100\% if Medtronic maintains the \$39 share price that existed at the time of the 2013 grant to Ishrak. But the details are not important. The point is that in states of the world in which Medtronic is successful and its share price rises, the grant is equivalent to time-vested restricted stock, but in states of the world in which Medtronic suffers in performance and share price, there is a risk that the grant will not vest and will be worthless. But to reiterate, since the relationship between Medtronic's earnings growth and share price is not fixed - there is only some correlation - one cannot plot actual payoff value against future share price, only an illustrative expected payout.

This payoff profile has something of the "hockey stick" look of the option payoff profile, suggesting some delta and vega in excess of those associated with conventional time-vested restricted stock. But the "optionality" here is not pronounced. The performance hurdle is not aggressive; the shares are likely to vest. The incentives created by this instrument are not that different from conventional restricted stock.

\footnotetext{
${ }^{87}$ Medtronic, Proxy Statement (Form DEF 14A), at 39.

${ }^{88}$ Danaher Corp., Proxy Statement (Form DEF 14A), at 47 (April 2, 2014).

${ }^{89}$ Danaher Corp., Proxy Statement (Form DEF 14A), at 47.

${ }^{90}$ Medtronic, Proxy Statement (Form DEF 14A), at 39.
} 


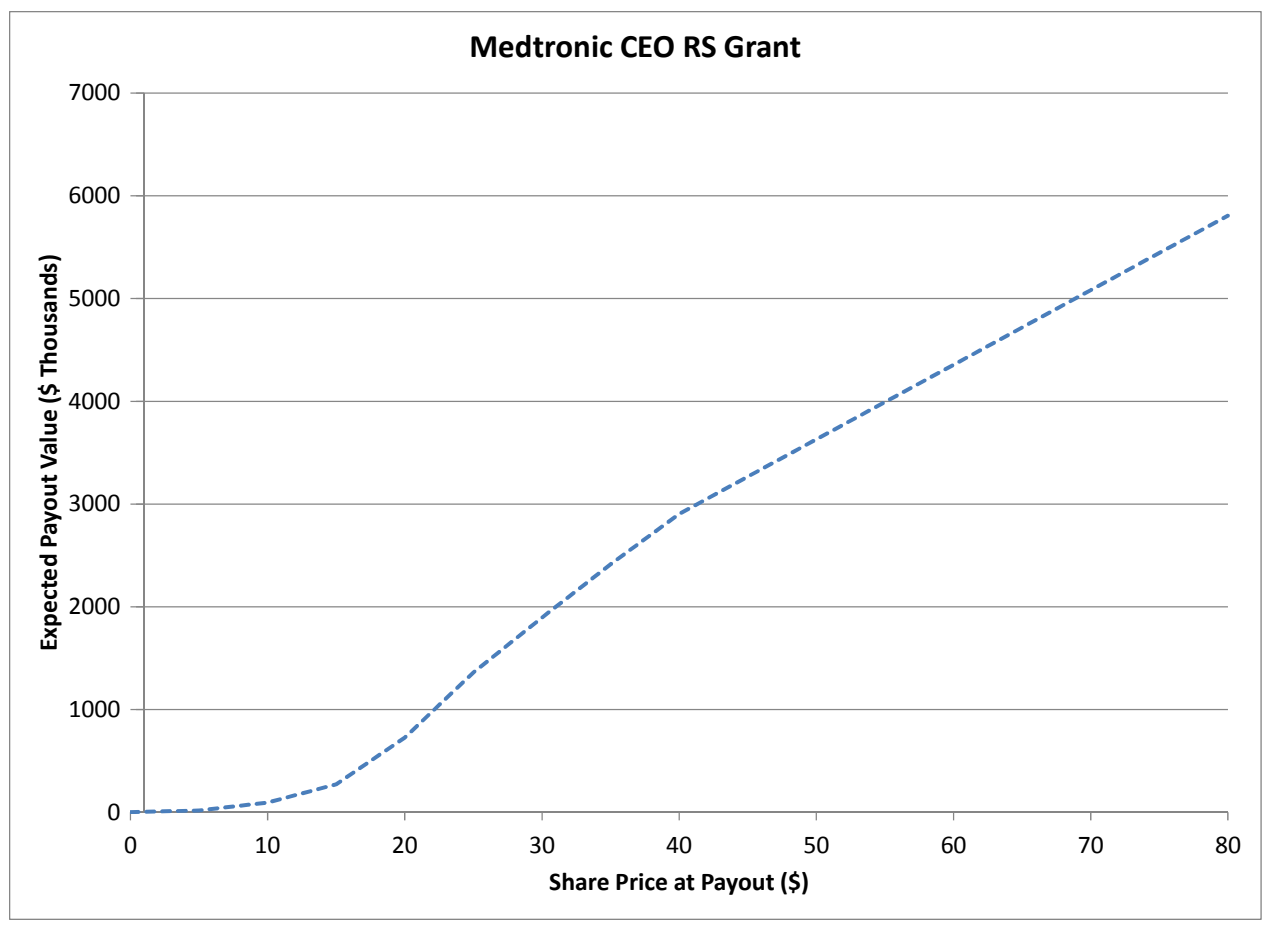

\section{Performance Shares}

We now turn to performance-based stock plans involving a variable share award, aka, performance shares. As noted, performance share plans may utilize any number of metrics and performance may be measured on an absolute or relative basis, or a plan may include both absolute and relative measures. To simplify exposition, I will focus on simple plans involving either absolute or relative metrics. ${ }^{91}$

\section{a. Absolute Metrics}

While details vary, performance share plans typically define a range of company performance that results in a smoothly increasing number of shares vesting at the end of the performance period, which is most commonly three years. ${ }^{92}$ Most plans include a performance threshold. If the threshold is not achieved, no shares are issued. Plans also include a cap on the number of shares issued that corresponds to a maximum performance level. Companies that employ profits, capital efficiency, revenue, and cash flow performance metrics generally look to company performance only, with no adjustment for peer or market performance. ${ }^{93}$ We'll call these absolute performance metrics. Plans employing relative performance metrics will be considered in the next subsection.

\footnotetext{
91 Well, not exactly. It turns out that Coke has recently added a relative metric to its plan and CenturyLink has adopted an absolute performance cap on payouts from its relative plan. These plans are complicated, but these two cases still provide helpful examples of the use of absolute and relative metrics.

${ }^{92}$ Cook (2014) at 14.

${ }^{93}$ Cook (2014) at 12.
} 
For example, Coca-Cola has issued performance share units to its senior executives for several years. ${ }^{94}$ For several years, the sole performance measure was compounded annual growth in economic profit. ${ }^{95}$ Each year, the compensation committee determined a threshold, target, and maximum profit growth performance level based on company-specific and macroeconomic factors. For their 2013 to 2015 plan, the threshold, target, and maximum profit growth levels were 4.4\%, 6.4\%, and 8.4\%. ${ }^{96}$ In 2013, Coke's CEO, Muhtar Kent, received performance share units of roughly 100,000 shares for threshold performance, 200,000 for target performance, and 300,000 for maximum performance. ${ }^{97}$ If the company fails to meet the threshold growth figure, he will receive no shares; if the company exceeds the maximum level, he will receive the maximum 300,000 shares. ${ }^{98}$ Between the threshold, target, and maximum performance levels, the number of shares issued is linearly interpolated. The relationship between profit growth and shares issued is described in figure $\mathrm{X}$.

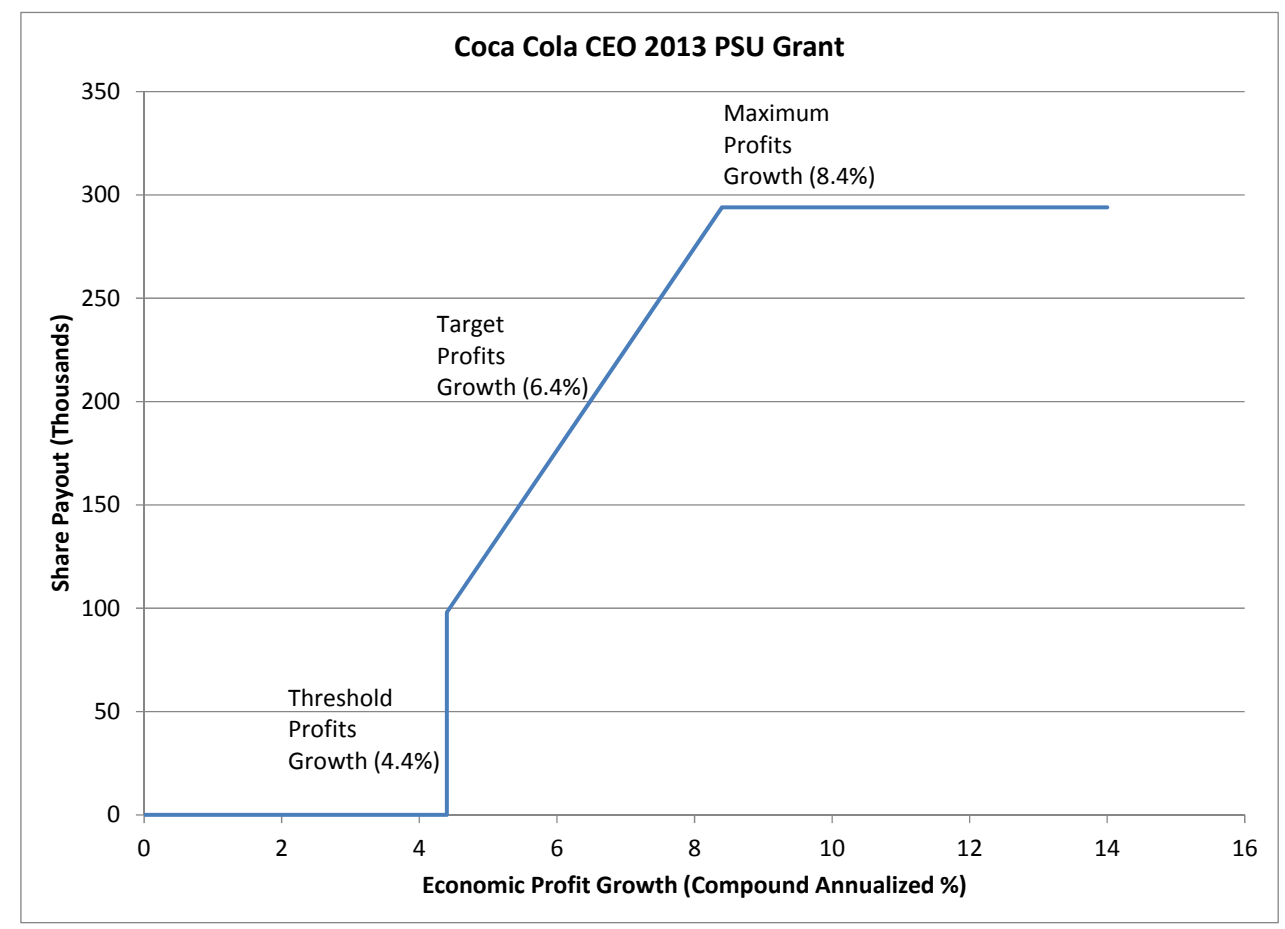

As the following chart demonstrates, the value of Kent's award at payout is a function both of the growth in profits and the share price at payout. Coke's shares traded between about \$36 and \$43/share in 2013.

\footnotetext{
${ }^{94}$ The Coca-Cola Company, Proxy Statement (Form DEF 14A), at 56 (2014 Proxy).

${ }^{95}$ The Coca-Cola Company, Proxy Statement, at 57. Coke added a relative total shareholder return metric to its plan beginning with the 2014-2016 performance period. Id at 58.

${ }^{96}$ The Coca-Cola Company, Proxy Statement, at 57.

${ }^{97}$ The Coca-Cola Company, Proxy Statement, at 68. The exact figures were 97,949, 195,898, and 293,847 shares, respectively.

${ }^{98}$ The Coca-Cola Company, Proxy Statement, at 57.
} 


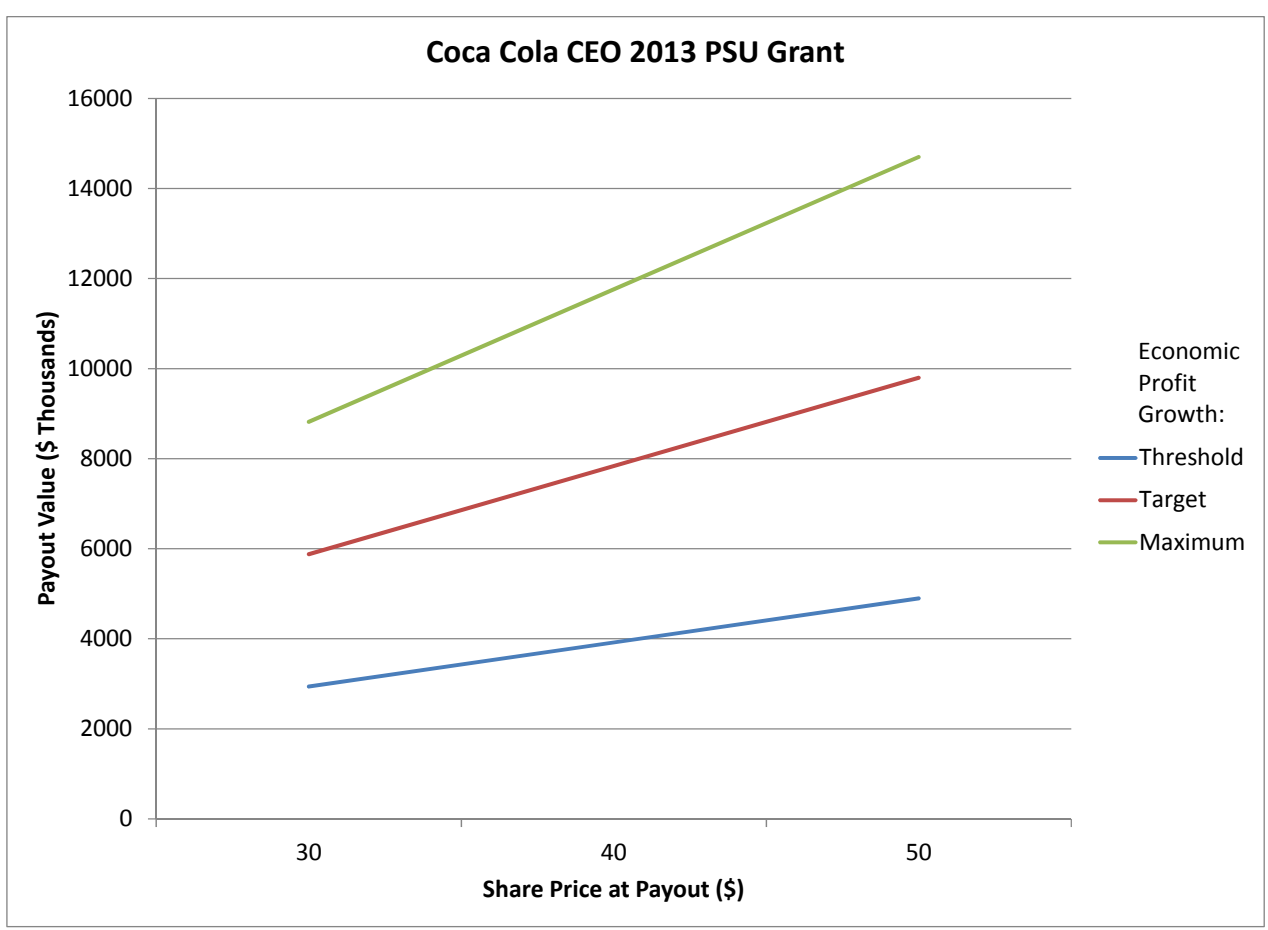

Of course, Coke's share price and profit growth at the end of three years are likely to be correlated. It is possible that Coke could meet or exceed its maximum profit growth target and suffer a drop in share price - the entire market could crash. It's also possible that Coke's profits could languish and that its shares could rise $25 \%$ with an overall market surge. In all probability, however, low profits growth will be associated with a low share price and high growth with a high share price. As in the case of the Medtronic's restricted stock grant, the relationship between share price at payout and expected payout value is probabilistic. The following figure illustrates one possibility. Simply for illustration, I have assumed that at a share price of $\$ 20$ or below, it is highly unlikely that the threshold profit growth target will have been met. At a share price of $\$ 60$ or beyond, I assume that the maximum target will have almost surely been met. In between, I assume an increasing likelihood that Coke will have achieved threshold, target, and maximum performance levels with increasing ex post share prices. In this hypothetical case, the relationship between share price at payout and the expected value of the CEO's PSUs is described by the solid line in the following figure. 


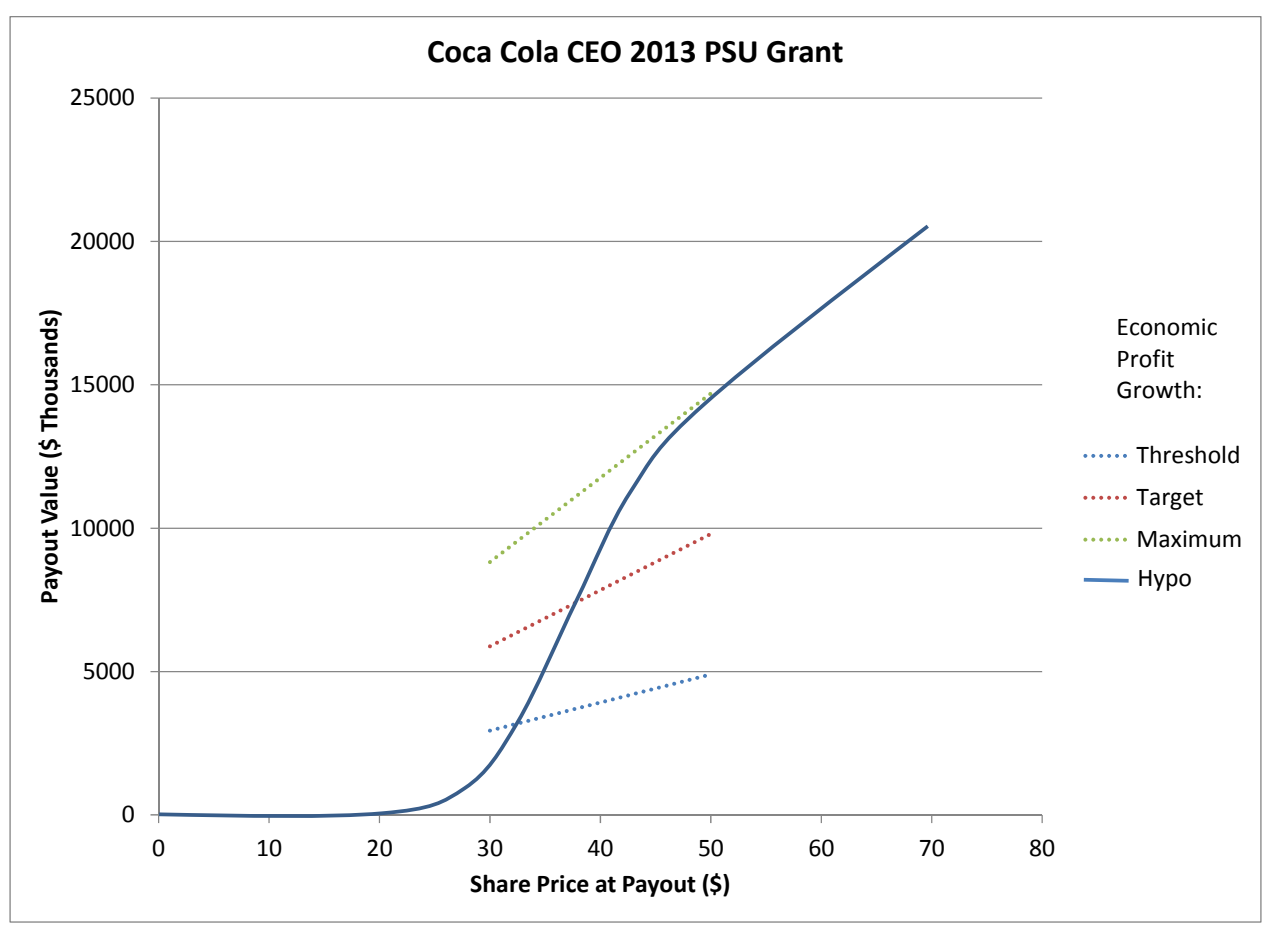

The most important thing to note here is the multiplier effect. As long as the performance measure and share price are correlated, higher performance levels result in the issuance of more shares and more valuable shares. This leverage effect is not a feature of conventional time-vested restricted stock. Also note the impact of the threshold performance level. The award is valueless (ex post) unless and until a minimum performance level is achieved. In combination, these features produce an economic relationship between share price and payoff that is very similar to that of an option, and this payoff profile more closely resembles the familiar "hockey stick" payoff profile associated with option compensation. The option lives!

BBCK have confirmed that performance-vesting conditions attached to restricted stock grants magnify the incentives created by these instruments. ${ }^{99}$ They analyzed the incentive properties of performance share units employing absolute metrics issued by a sample of large public companies between 1998 and 2008. BBCK found that the addition of one accountingbased metric, similar to the Coke plan, increased the delta of awards by an average of $72 \% .{ }^{100}$ BBCK also found that performance share plans with a single accounting-based metric delivered substantial vega, whereas conventional time-vested restricted stock grants create no vega. ${ }^{101}$

\footnotetext{
${ }^{99}$ BBCK (2013).

${ }^{100} \mathrm{BBCK}$ (2013) at 65 (table 6, panel C).

${ }^{101}$ BBCK (2013) at 67 (table 7, panel C). See supra note $\mathrm{x}$ and accompanying text for discussion of delta and vega.
} 


\section{b. Relative Metrics}

Increasingly, performance share plans measure performance relative to that of a peer group or the overall market. ${ }^{102}$ Total shareholder return (TSR) - the increase in a company's stock price plus dividends over some period - is a popular metric for performance share plans, and the large majority of TSR plans employ a relative measure of TSR. ${ }^{103}$ Aside from the comparative feature, the mechanics of these plans are generally quite similar to the Coca-Cola plan we just reviewed. CenturyLink, a large telecom company, utilizes a typical relative TSR plan. ${ }^{104}$ Under the CenturyLink plan, executives receive performance-vested restricted stock that vests only if time and variable relative TSR performance hurdles are met. ${ }^{105}$ The reference group is the S\&P 500. A threshold level of stock will vest after three years if CenturyLink's TSR over that period is at the $25^{\text {th }}$ percentile of S\&P 500 TSR. $50^{\text {th }}$ percentile TSR performance results in a target level of stock vesting. $75^{\text {th }}$ percentile TSR performance results in maximum vesting. No shares vest if CenturyLink's TSR rank is less than $25^{\text {th }}$ percentile and no additional shares vest for performance ranking in excess of the $75^{\text {th }}$ percentile. Vesting levels are linearly interpolated for relative TSR performance between the $25^{\text {th }}$ and $75^{\text {th }}$ percentile. However, while the basic performance measure is relative shareholder return, there is also an absolute performance overlay. Under the CenturyLink plan, if absolute TSR over the relevant period is negative, no more than the target number of shares may vest. ${ }^{106}$

The threshold, target, and maximum restricted shares issued to CenturyLink's CEO, Glen Post, in 2012 were 29,422; 58,844; and 117,688. ${ }^{107}$ The relationship between CenturyLink's relative TSR performance and the number of Post's shares that will vest in three years (assuming he remains employed as CEO and the company achieves positive absolute TSR) is portrayed in the following figure.

\footnotetext{
102 J. Carr Bettis, John Bizjak, Jeffrey Coles \& Brian Young, The Presence, Value, and Incentive Properties of Relative Performance Evaluation in Executive Compensation Contracts 10 (working paper, Feb, 2014) (hereinafter BBCY) (finding increased usage of RPE in performance based equity awards in a sample of 750 large companies between 1998 and 2012 with 37\% of firms making RPE awards in 2012, and finding that of firms making performance-based equity awards in 2012, about half included RPE provisions).

${ }^{103}$ Cook (2014) at 12.

${ }^{104}$ CenturyLink, Inc., Proxy Statement (Form DEF 14A) (2013).

${ }^{105}$ CenturyLink (2013 Proxy) at 55.

${ }^{106}$ CenturyLink (2013 Proxy) at 55. It appears from the proxy that the target number of shares is issued to a plan participant, but that a fewer or greater number of shares will vest depending on performance. This seems to be a hybrid between a true restricted stock plan and a restricted stock unit plan. The number of shares that is issued could be important because these shares carry voting rights unless and until forfeited. Id. Accrued dividends are paid at vesting depending on the number of shares that actually vest. Id.

${ }^{107}$ CenturyLink (2013 Proxy) at 54.
} 
The Way We Pay Now

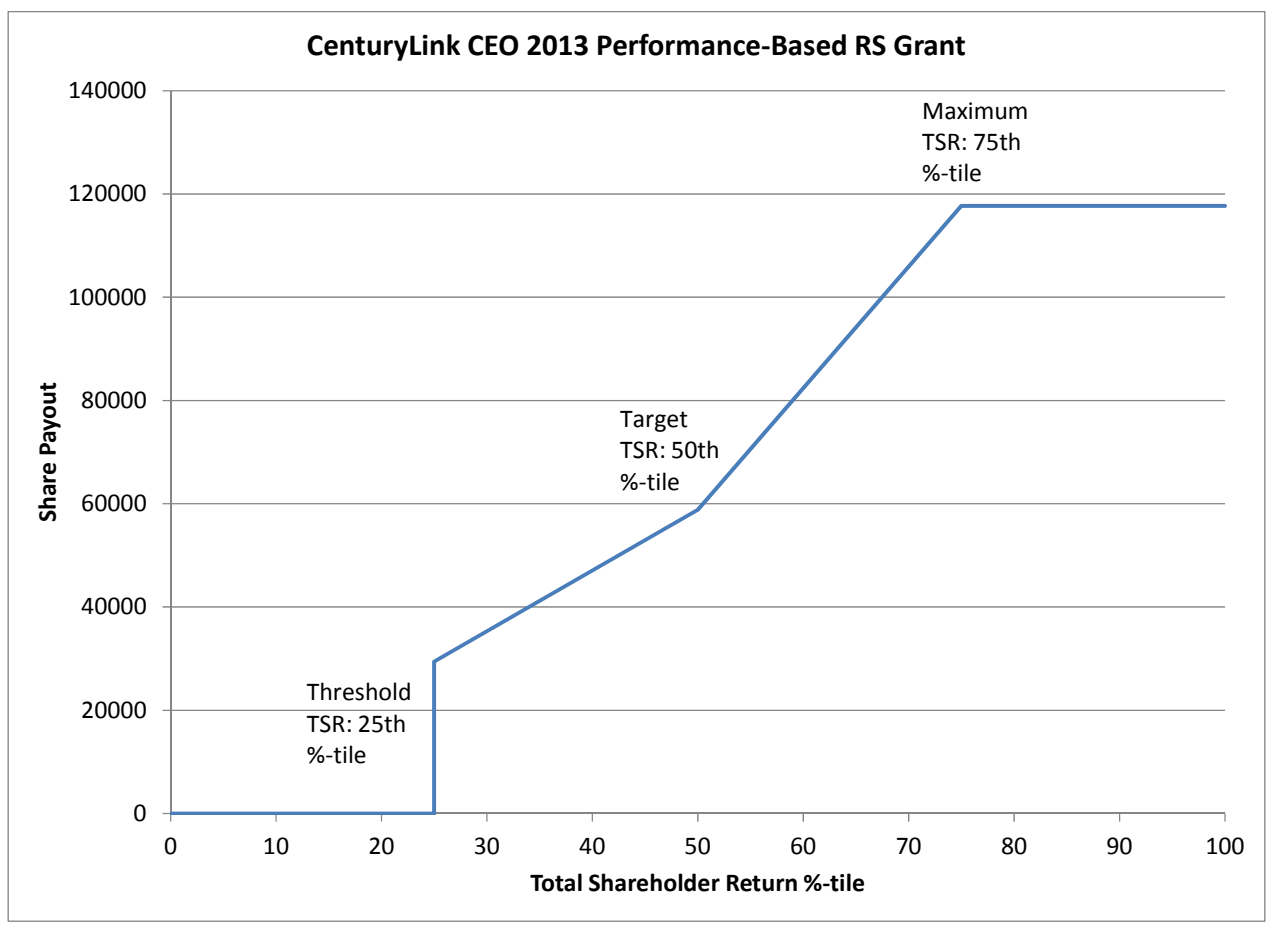

As before, the value of the CEO's stock award at payout is a function of both relative TSR performance and share price. CenturyLink's shares traded between about \$37 and $\$ 43 /$ share in 2012. Let’s call it $\$ 40 /$ share as a baseline.

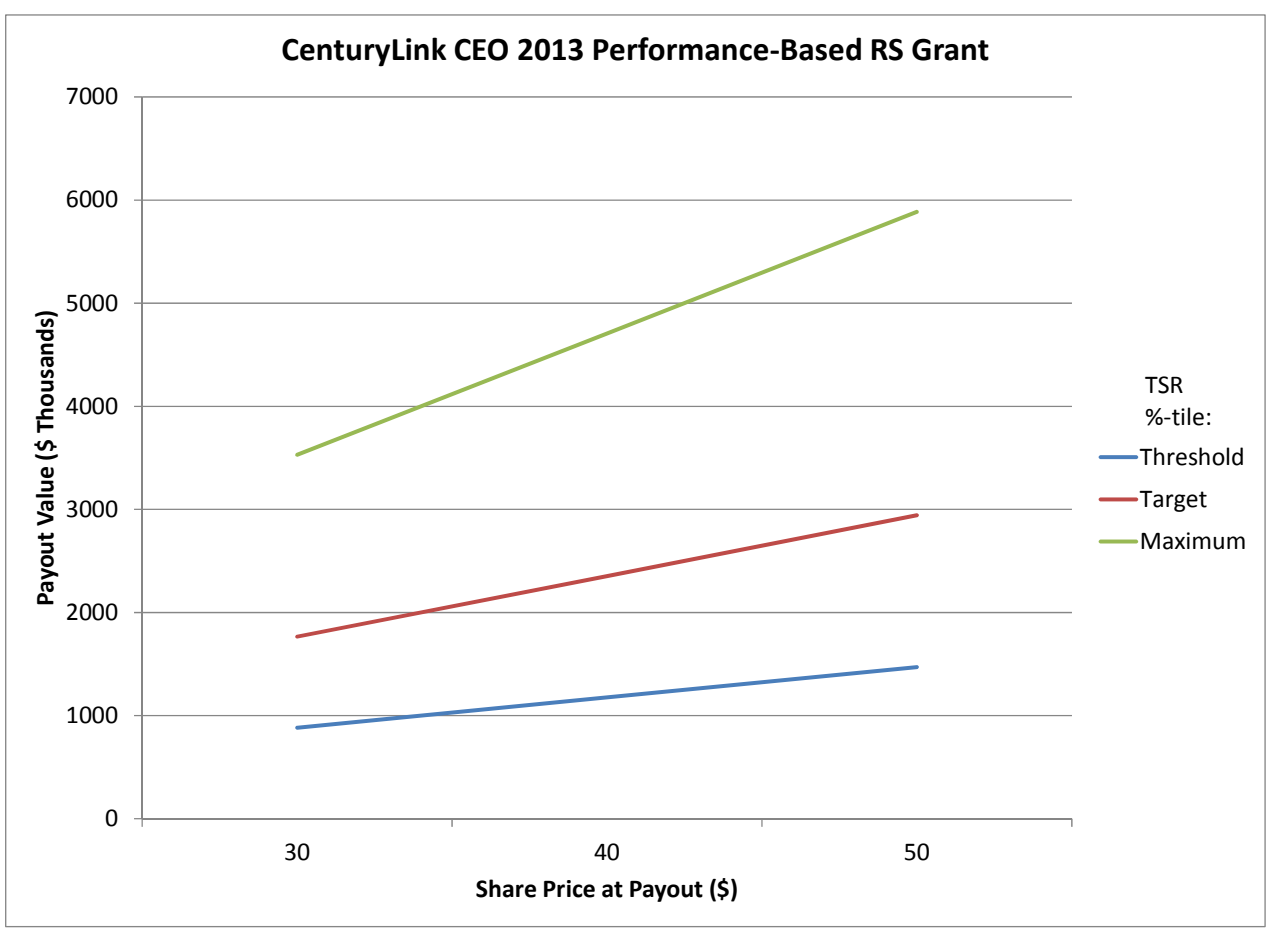

But also as before, the performance measure and share price are correlated. In this case, TSR and share price are highly correlated. TSR is share price (plus dividends). The 
complication here is that the performance measure isn't CenturyLink's absolute TSR performance, but relative TSR performance.

Let's begin by assuming that the S\&P 500 index is flat over the three year period. In that case, assuming that CenturyLink pays an average level of dividends, maintaining a $\$ 40$ share price over three years should represent $50^{\text {th }}$ percentile TSR performance. A lower share price would place CenturyLink in the bottom half of performers. For illustration, let's assume that a $\$ 30$ share price (a $25 \%$ drop) represents $25^{\text {th }}$ percentile TSR performance relative to the S\&P 500. Conversely, let's assume that a $25 \%$ increase in CenturyLink's share price to $\$ 50 /$ share represents $75^{\text {th }}$ percentile performance. The relationship between share price and value to Post at payout in this illustrative case is portrayed in the following figure. ${ }^{108}$

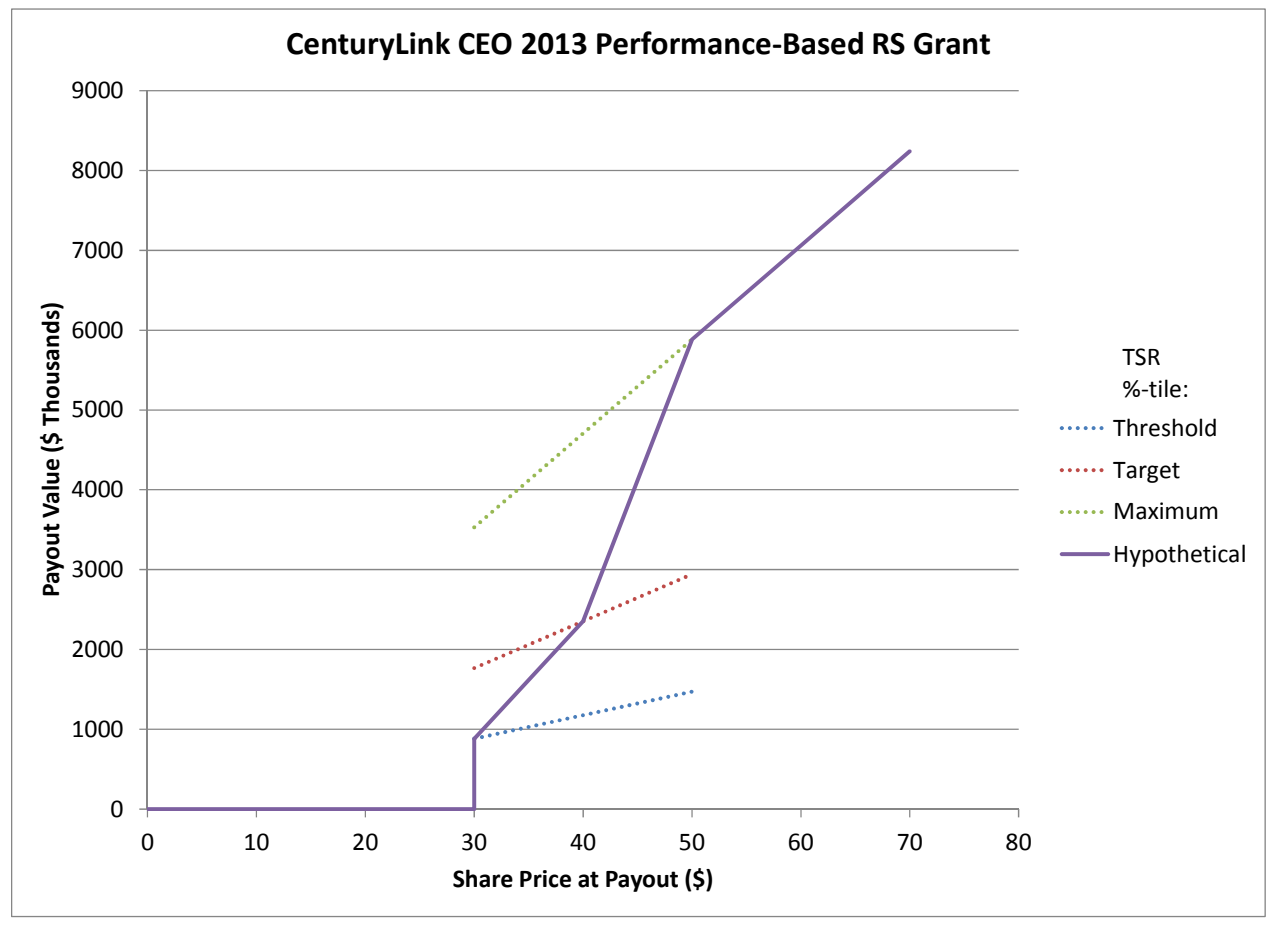

So far, the picture at CenturyLink looks very similar to that at Coca-Cola, but recall that CenturyLink employs a relative TSR metric. Suppose that the S\&P 500 index rises by 25\% over the three year performance period. Now for CenturyLink to maintain $50^{\text {th }}$ percentile TSR performance (again assuming average dividend yields), its share price must rise by $25 \%$ to \$50/share. Under an absolute TSR plan, an increase to \$50/share might have yielded maximum vesting; under a relative TSR plan in a bull market, only target vesting. The relationship between share price and value under these two scenarios (flat S\&P 500 and S\&P 500 up 25\%) is portrayed here. Again, the exact relationship between performance and percentiles is unknown. This graph is purely for illustration.

\footnotetext{
${ }^{108}$ Under this relative TSR approach, a specific ex post share price will represent $25^{\text {th }}$ percentile performance and there will be an abrupt change in payoff at that point. On an ex ante basis, one could smooth these curves to reflect expected payoffs.
} 


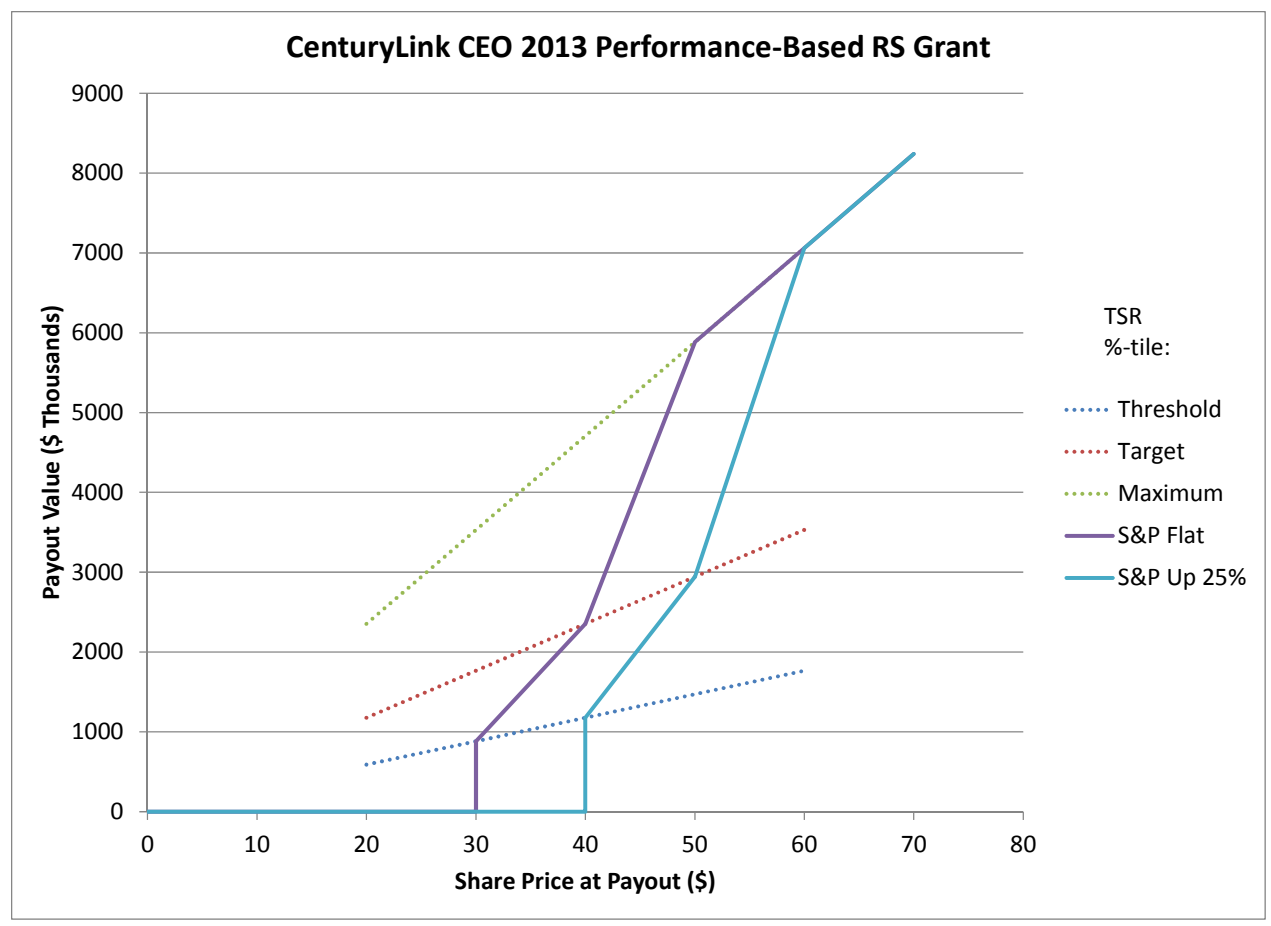

Of course, the S\&P 500 can also decline over the performance period, in which case simply maintaining a $\$ 40$ share price at CenturyLink would represent superior performance. Under this relative TSR plan, participants would indeed receive more shares and more value for maintaining a flat $\$ 40$ share price when the S\&P 500 is down $25 \%$ than in scenarios in which the $\mathrm{S} \& \mathrm{P}$ is flat or rising, as seen here.

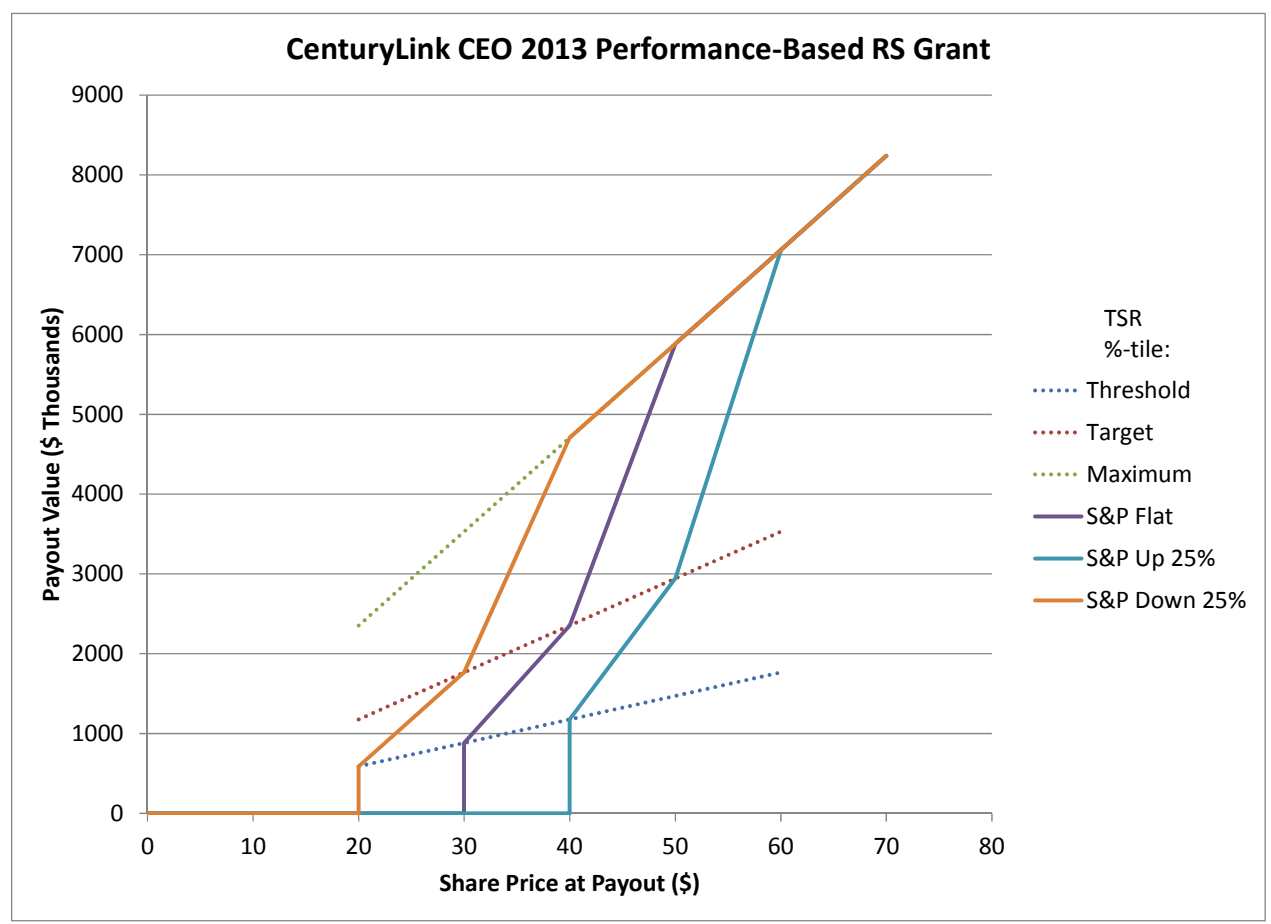


This, of course, is the point to using relative TSR performance in these plans. Relative TSR plans increase the linkage between pay and firm-specific performance. Executives are rewarded or penalized to a much lesser degree for overall market rises or declines than they would be under an absolute TSR plan, or, for that matter, if they held conventional options.

By now, it may be apparent that a relative TSR performance share plan is very similar economically to an indexed stock option - an option with an exercise price that rises or falls with the rise or fall in an index. ${ }^{109}$ The relative TSR plan here is similar to an option with a strike price that rises or falls with the S\&P 500 share index.

\section{B. Performance-Based Option Plans}

The option analogs of performance-accelerated and performance-vested stock are occasionally used by large public companies. Performance-accelerated options were more commonly observed in the late 1990's/early 2000's than performance-accelerated restricted stock, but these instruments have virtually disappeared today. ${ }^{110} 80$ firms in BBCK's sample (6\%) issued performance-accelerated options in 1999, but only one firm did so in 2012.111

Vesting of performance-vested options is made contingent on the satisfaction of performance criteria as well as the passage of time. ${ }^{112}$ As with performance-vested restricted stock, performance metrics may include a variety of share price or accounting-based measures, and measurement may be made on an absolute or relative basis. While more common than performance-accelerated options today, these instruments are much less frequently observed than performance-based stock. In BBCK's sample, only 59 of the firms in BCK's sample (5\%) issued performance-vested options in 2012. ${ }^{113}$

Conventional stock options already provide executives with significant incentives to increase shareholder value (delta) and to increase volatility, perhaps by taking on risky projects (vega). However, BBCK found that adding performance-vesting conditions to options substantially increased both delta and vega. ${ }^{114}$

\section{Performance Cash Plans}

Adding to the heterogeneity of modern executive pay design, a small number of firms utilize multi-year cash-based performance plans. These plans incorporate performance metrics accounting and/or share value based - that are similar to those observed with performance share plans, and performance measurement may be done on an absolute or relative basis. The BBCK

\footnotetext{
109 Supra.

110 BBCK (2013) at 58 (Table 2, Panel A).

111 BBCK (2013) at 58 (Table 2, Panel A).

112 Hay Group (2013) at 20. For an example of a performance-vested option plan, see HP's 2015 proxy statement at pages 64 to 65 (describing vesting conditions for performance-contingent stock options based on share price appreciation or alternatively relative TSR performance).

113 BBCK (2013) at 58 (Table 2, Panel A).

114 Holding the value of the grant constant, BBCK found that adding one accounting (stock price) metric increased delta by 97\% (30\%) and increased vega by 314\% (42\%). BBCK (2013) at 64-67 (Tables 6 \& 7).
} 
study did not include performance-cash plans, but the Hay Group's recent study indicates that $16 \%$ of the 300 firms studied made performance cash grants in 2012 (versus 78\% issuing performance-based stock and 5\% issuing performance-based options). ${ }^{115}$ In addition, single year cash-based performance plans are a very common element of executives' annual incentive packages.

Cash performance plans also provide incentives (direct or indirect) to increase shareholder value. However, they lack the leverage associated with the variable share performance share plans that have evolved as the single most important element, in aggregate, in top executive pay at the largest U.S. firms. Given that fact, the remainder of this paper will focus on the benefits, and potential burdens, of performance-based stock plans. To some extent, however, the benefits of performance-vested options and performance cash plans, and the concerns, are analogous to those of performance-based stock.

\section{Performance-Based Executive Compensation - An Initial Assessment}

\section{A. Advantages of Performance-Based Stock Plans}

Performance-based stock plans have several features that make them attractive as incentive compensation for senior executives. Chief among these is flexibility.

As we have seen, although they are nominally stock plans, performance-based stock plans can be designed to provide the kinds of high-powered incentives that we associate with options - strong incentives to increase share prices and incentives to take on risk. In their recent work, BBCK find that the aggregate vega (the risk-taking incentive associated with compensation) provided by performance-vesting conditions attached to senior executive stock and option grants more than made up for the aggregate decline in conventional stock option use in the mid-2000s and the vega associated with these options. ${ }^{116}$ In earlier work, Hayes, Lemmon, and Qiu had found little evidence that the decline in option use in the mid-2000s was associated with firms adopting less risky financial and investment policies. ${ }^{117}$ This was surprising, and Hayes, Lemmon, and Qiu interpreted their findings as suggesting that the riskinducing properties, or "convexity", of options actually does little to align manager incentives with shareholder preferences with respect to risk. ${ }^{118}$ But an alternative explanation, supported by BBCK's evidence, is that the aggregate level of convexity has been maintained, just with a different form of compensation. ${ }^{119}$

\footnotetext{
115 Hay Group (2013) at 21.

116 BBCK (2013) at 36 and Figure 5.

${ }^{117}$ Rachel M. Hayes et al, Stock Options and Managerial Incentives for Risk Taking: Evidence from FAS $123 R, 105$ J. Fin. Econ. 174, 176 (2012).

${ }^{118}$ Hayes et al, supra at 176.

119 BBCK (2013) at 37.
} 
Performance-based compensation utilizing relative performance metrics explicitly adopts relative performance evaluation, a feature of long-proposed, but very rarely observed, indexed options. As we've noted, adding RPE to compensation contracts should increase efficiency by better focusing pay on performance within managerial control. As a substitute for conventional options, relative performance-based plans can maintain high powered incentives while eliminating windfalls from bull markets and mitigating the problem of a bear market undermining those incentives. ${ }^{120}$ To be sure, commentators have suggested some reasons, aside from accounting and tax, that firms might forego the opportunity to index options, but none of these is terribly convincing. ${ }^{121}$ The ability to explicitly incorporate RPE into incentive contracts is a clear plus for performance-based equity pay.

Performance share plans also can be designed to be effectively in-, at-, or out-of-themoney. Recall that an at-the-money option is issued with strike price equal to the market price of the stock at the date of grant. The stock price must increase for the award to have value ex post. Ignoring upward drift in share prices, as well as value-enhancing steps taken by the firm, one could think of an at-the-money option as one with a 50/50 chance of being exercised in the money. ${ }^{122}$ And one could think of a performance share plan in which there is a 50/50 chance of vesting as also being "at-the-money."

Consider the Medtronic performance-vested restricted stock plan. Given the lack of variable share levels - it's all or nothing - this plan is based on relatively easily achievable performance hurdles. ${ }^{123}$ The probability of these shares vesting is significantly greater than $50 \%$. Economically, this is similar to a far in-the-money stock option. If the shares are almost certain to vest, the value of the award rises and falls with the underlying share price.

The relative total shareholder return (TSR) plan operated by CenturyLink is also analogous to an in-the-money option. ${ }^{124}$ Recall that CenturyLink need only achieve $25^{\text {th }}$ percentile TSR performance for a threshold level of shares to vest. A higher target level of shares vests with $50^{\text {th }}$ percentile performance. All else equal, there should be a 50/50 chance of

\footnotetext{
120 See supra note $\mathrm{x}$ and accompanying text.

121 BFW at 803-809 (reviewing and critiquing proffered explanation for failure to index options, including suggestions that non-indexed options assist firms in retaining executives during bull markets and foster implicit collusion within certain industries). As noted supra note x, Dittmann, Maug \& Spalt and Chaigneau, Edmans \& Gottlieb show that option indexation reduces incentives (delta) and suggest that the cost of maintaining incentives through issuing additional options may be prohibitive. I would assume, however, that adopting relative performance hurdles for stock plans has a similar impact on delta, and yet many firms are embracing this approach. It seems more likely that tax, accounting, or executive perceptions inhibited firms from issuing indexed options.

122 Assuming 30\% volatility, a 5\% interest rate, and no dividends, a 3-year at-the-money option has about a 51\% probability of closing in the money. This is based on a European call option.

123 See supra note $\mathrm{x}$ and accompanying text.

124 See supra note $\mathrm{x}$ and accompanying text.
} 
achieving $50^{\text {th }}$ percentile performance and the inclusion of a lower threshold target puts this instrument in the money at grant. ${ }^{125}$

In their study of performance share plans employing absolute performance metrics between 1998 and 2008, BBCK found that threshold performance was actually achieved in only $47 \%$ of the cases. ${ }^{126} 53 \%$ of the time, no shares vested. On average, then, these plans seemed to be slightly out-of-the-money, at least in hindsight. We do not have analogous ex post data for relative performance share plans, but one might expect that these plans are more likely to be equivalent to in-the-money options simply because of the common practice of using $50^{\text {th }}$ percentile performance as a target for relative performance, with lower and higher percentiles equating to threshold and maximum performance. This supposition is bolstered by simulations conducted by BBCY predicting that threshold performance in RPE plans will be achieved in 69$76 \%$ of cases and that target performance would be achieved in $48-53 \%$ of cases. ${ }^{127}$

There is nothing inherently objectionable about in-the-money pay instruments. As noted above, researchers have found that in-the-money design is optimal in certain circumstances. ${ }^{128}$ The advantages of an in-the-money design are that payouts are more certain and that the instrument continues to provide useful incentives over a greater range of ups and downs in company and market performance. Of course, in-the-money instruments are more costly to grant than at- or out-of-the-money instruments, so fewer of these instruments should be issued, all else being equal.

The overall theme here is that performance share plans offer tremendous flexibility in design that allow firms to issue pay instruments across the "moneyness" spectrum and, importantly, to mimic indexed options with relative performance metrics, as we saw with the CenturyLink plan. There are two reasons that performance share plans are more flexible than conventional stock and options. First, the moneyness of a performance share unit - particularly one employing absolute performance metrics - is not as obvious as it is with conventional equity. Absent backdating or other fraud, a conventional executive stock option issued by a company with publicly traded shares is clearly and transparently issued at-, in-, or out-of-the-money. The "moneyness" of a conventional option is almost impossible to conceal. One need only compare the option exercise price with the current stock market price to determine the moneyness. But employees who might object to receiving an out-of-the-money conventional stock option are

\footnotetext{
${ }^{125}$ In reality, because executives help determine plan design and plan metrics, we might expect firms to achieve $50^{\text {th }}$ percentile performance targets more than $50 \%$ of the time. As a result, these plans may be further in the money than they appear on the surface.

${ }^{126}$ BBCK (2013) at Table 3 (reporting ex post frequencies of performance attainment as well as simulated ex ante probabilities).

${ }^{127}$ BBCY at Table 6.

${ }^{128}$ See supra note $\mathrm{x}$ and accompanying text.
} 
unlikely to realize that a performance share plan like Coke's, for example, is effectively out of the money. ${ }^{129}$ Of course, there's a cost to this opacity, which will be explored below.

Second, the tax constraints that bar in-the-money and indexed options do not bar their effective replication with performance shares. This is a technical point, but it is important in practice. Under IRC § 409A, vested deferred compensation (broadly defined) that runs afoul of certain requirements is currently includable in income and subject to a $20 \%$ penalty tax. ${ }^{130}$ Congress enacted $\S 409 \mathrm{~A}$ in an effort to combat what it viewed as improper deferrals of income for tax purposes. One particular concern was that executives had too much control of the timing of the receipt of their deferred compensation. ${ }^{131}$ Although stock options could be viewed as providing for deferral of compensation and could have been fully subjected to $\S 409 \mathrm{~A}$, the regulations provide a safe harbor exclusions for options. ${ }^{132}$ But the option safe harbor does not apply to in-the-money or indexed options. It applies only if "the exercise price may never be less than the fair market value of the underlying stock... on the date the option is granted." 133 In-themoney options are issued with an exercise price less than fair market value at grant, so they obviously violate this restriction, and indexed options may have an exercise price less than fair market value at grant (if the index moves down), so these instruments fall out of the safe harbor, as well.

Deferred compensation that is not within a safe harbor - including in-the-money options, indexed options, and performance share plans - is subject to the rules of $\S 409 \mathrm{~A}$. Options are problematic under $\S 409 \mathrm{~A}$ because the employee controls the timing of exercise. This is not a permissible distribution under $\S 409 \mathrm{~A}$, which allows penalty-free distributions from deferred compensation plans only in the events of death, disability, a predetermined fixed distribution date, change in control, and unforeseeable emergency. ${ }^{134}$ Because performance share plans have a certain payout date, they do not result in impermissible distributions, and thus firms utilizing performance share plans need not worry about particular design features (e.g., moneyness) that otherwise could trigger the penalty tax. ${ }^{135}$

\footnotetext{
${ }^{129}$ I actually have no idea whether Coke's plan is in-, at-, or out-of-the-money. That's my point. One would have to have a feel for the likelihood of achieving the absolute profit growth metrics included in the plan to assess its "moneyness."

130 IRC 409A(a).

131 See H.R. Rep. No. 110-658, at 39 (2008) (modifying § 409A and discussing its purposes). Section 409A has been severely criticized for its ineffectiveness and complexity. See Gregg D. Polsky, Fixing Section 409A: Legislative and Administrative Options, 57 Vill. L. Rev. 635 (2012); [Doran].

132 Treas. Reg. § 1.409A-1(b)(5)(i)(A) (as amended in 2007). Section 409A does not apply to time-vested restricted stock. Treas. Reg. § 1.409A-1(b)(6)(i).

133 Treas. Reg. § 1.409A-1(b)(5)(i)(A)(1).

134 IRC § 409A(a)(2).

135 To be sure, in the money or indexed options could be issued with fixed exercise dates, but I am not aware of any instance of compensatory options being issued with a fixed exercise date. In all cases, the optionees have discretion to exercise between vesting and expiration. Why exercise timing discretion is ubiquitous is an interesting question that is beyond the scope of this article. The answer could be simple path dependence or something more nefarious. Placing the timing of options exercise in the hands of executives enables them to use inside information in timing
} 
Of course, performance share plans provide flexibility in other ways as well. While conventional stock and options tie rewards directly to share prices, and share prices only, performance share plans can include other performance metrics. The scope to do so is unlimited. While the ultimate (economic) concern of investors is share price, it is conceivable that tying executive rewards more directly to sales growth, EPS, and similar metrics over the medium term is a more effective way of achieving high shareholder returns than focusing directly and exclusively on share prices. This idea relates back to the concept that the most efficient incentive schemes tie rewards to performance that is within the managers' control. ${ }^{136}$ Managers have more control over sales and earnings than over the price of their stock, particularly given swings in the market, so using alternative metrics in performance share plans could represent an improvement, although, to be sure, relative TSR plans also eliminate the risk of market price swings from executive pay contracts.

Consistent with this rosy view, BBCK provide evidence that the issuance of performance-based equity awards is consistent with "contracting to promote CEO fit, incentive alignment, and sorting." 137

\section{B. Challenges Raised by Performance-Based Equity Pay}

The flexibility of performance share plans is both a feature and a bug. Often these plans are highly complex, and grant date valuation is difficult even for the simplest of performance share plans. In addition, in some ways performance share plans are more gameable than conventional stock and option compensation. Another current problem with performance share plans is that the accounting treatment differs significantly depending on the metrics utilized, likely leading to accounting-driven design choices. Moreover, neither of the currently applicable accounting regimes is likely to produce reported compensation expense that matches the expected or actual value transferred to executives.

\section{Heterogeneity, Complexity, and Related Challenges}

Observed performance share plans rely on a broad range of performance measures, including both share price-related metrics and accounting-based metrics, such as profit, capital efficiency, revenue, and cash flow measures. Within each of the accounting-based metric categories, one can find many different specific metrics. For example, profit measures include EPS, EBITDA, net income, operating income, pre-tax profit, etc. ${ }^{138}$ Some plans adopt a single performance metric; other plans utilize several metrics. ${ }^{139}$ Moreover, as we have seen, some of these plans base payouts on absolute performance, while others measure performance relative to

exercise and sale of the underlying shares, which may be a low salience means of boosting executive pay. I thank Gregg Polsky for highlighting this issue.

${ }^{136}$ See supra note $\mathrm{x}$ and accompanying text.

${ }^{137}$ J. Carr Bettis, John Bizjak, Jeffrey Coles \& Swaminathan Kalpathy, Stock and Option Grants with Performancebased Vesting Provisions, Rev. Fin. Studies 4 (2010).

${ }^{138}$ Frederic W. Cook \& Co., Inc., The 2013Top 250 Report 9 (2013) (hereinafter Cook (2013)).

139 About half of the companies in F.W. Cook's sample employed multiple metrics in their performance-based equity plans in 2013. See supra note $\mathrm{x}$ and accompanying text. 
a peer group. ${ }^{140}$ It is very difficult to find two performance share plans with the same metrics. While this variety of approaches may reflect optimal matching of incentive schemes with firms, it makes firm-to-firm comparisons extremely difficult.

Adding to the comparability problem is the inherent difficulty of estimating the value of performance share grants ex ante. Compare conventional options. Several well-accepted valuation methods for conventional options have been developed over the years and are recognized as acceptable techniques by FASB. ${ }^{141}$ Many firms utilize Black-Scholes option valuation methodology. Black-Scholes is not a perfect fit for non-transferable, compensatory stock options, but by substituting an expected holding period for the contract term of a traded option, Black-Scholes provides a reasonable estimate of ex ante value (as well as of option delta and vega, which are important measures of incentive properties). ${ }^{142}$ Other firms utilize binomial or lattice models to value compensatory options, while still others rely on Monte Carlo simulations. These are all accepted valuation methods for compensatory options.

To be sure, the outputs from these models are only as good as the inputs, and firms have significant discretion in selecting assumptions with respect to stock price volatility, interest rates, and dividend yields. Not surprisingly, firms tend to use this discretion to reduce the reported grant date "fair value" of executive stock options. ${ }^{143}$ Nonetheless, as a result of option valuation innovations over the last several decades, observers are now able to calculate and firms are required to disclose a reasonably accurate and verifiable grant date value for a class of instruments that recently accounted for more than half of aggregate executive pay at large public companies.

The substitution of performance-based equity for conventional options represents a step backward, at least initially, in terms of accuracy of valuation and disclosure of executive pay. Some stock option valuation methods can be adapted to the valuation of performance share plans that are based solely on stock price or stock market measures. ${ }^{144}$ For example, CenturyLink uses a Monte Carlo simulation to generate ex ante values for grants made under its relative TSR

\footnotetext{
${ }^{140}$ See supra note $\mathrm{x}$ and accompanying text.

141 ASC 718-10-55-16 (acceptable valuation techniques include, but are not limited to, lattice (i.e., binomial) models, closed form (i.e., Black-Scholes-Merton) models, and Monte Carlo simulations).

142 ASC 718-10-55-18. See also, SFAS 123R, Appendix B (discussing the bases for the FASB's decision to mandate fair value accounting for options). The Black-Scholes value of an option can be thought of as the discounted present value of the expected value of the option at payout.

${ }^{143}$ See Eli Bartov et al., Stock Option Expense, Forward-Looking Information, and Implied Volatilities of Traded Options (Working Paper, Apr. 2004), available at http://ssrn.com/abstract $=510042$ (finding that firms opportunistically selected volatility measures to reduce reported compensation); Leslie David Hodder et al., Using Valuation Model Inputs to Manage Employee Stock Option Disclosures (Working Paper, Apr. 2004), available at http://www.usc.edu/schools/business/FBE/FEA2004/FEApapers/A-S6_MLMcANALLY.pdf. (finding use of discretion to reduce pro forma earnings among a subset of firms); but see Steven Balsam et al., Managing Pro Forma Stock Option Expense under SFAS No. 123, 17 ACCT. HoRIZONS 31 (2003) (finding little evidence of manipulation of overall option expense but finding manipulation of allocation of expense to minimize the first year impact).

${ }^{144}$ ASC 718-10-55-17.
} 
plan. ${ }^{145}$ But valuing grants made under a relative TSR plan is more complex than valuing a conventional option. Different and potentially more manipulable assumptions are required such as the cross-volatility between a firm's share price and that of the relevant index or basket of stocks.

The grant date valuation difficulties increase substantially when accounting-based performance measures are added to the mix. Apparently, the FASB has concluded that there is currently no reliable approach for calculating the value of these instruments ex ante. ${ }^{146}$ As a result, the FASB has adopted a different approach to accounting for these instruments, which does not require any adjustment to grant date "fair value" on account of the incorporation of such hurdles. ${ }^{147}$ Instead, firms are required to estimate the number of shares that are most probable to vest given the performance hurdle. This approach, which provides firms with tremendous discretion over reported executive pay levels, is further discussed below. ${ }^{148}$

The bottom line is that grant date valuation of performance-based equity grants is not highly reliable. It is significantly less reliable than ex ante valuation of conventional options. And we should not expect misreporting to be random. Firms will tend to use discretion in choosing valuation methods and assumptions to reduce, not increase, reported executive compensation and overall firm compensation expense. For example, in their study of performance share plans employing absolute performance metrics between 1998 and 2008, BBCK found that the median firm underreported the ex ante value of share price-based grants by 25\%. ${ }^{149}$ One pay consultant describes relative total shareholder return plans, such as the plan utilized by CenturyLink, as being "expense efficient," meaning that the expense that must be reported under GAAP is relatively low compared with the value delivered to the executives. ${ }^{150}$ At least they are honest about it.

\footnotetext{
145 CenturyLink (2013 Proxy) at 53.

146 BBCK (2013) at 29.

147 ASC 718-10-55-64.

148 See infra TAN x. In a nutshell, the performance condition is ignored in determining the grant date "fair value" and is subsequently taken into account by adjusting the accounting expense for any shares that failed to vest because the performance condition was not satisfied. ASC 718-10-30-12.

149 BBCK (2013) table 5. BBCK also found that the firms in their study over reported the ex ante value of grants contingent on accounting metrics by about 19\%. BBCK were puzzled by the over reporting of grant date "fair value" for this class of instrument. The accounting treatment for these instruments is described further in the following section. See also, Alexander Merz, Expensing Performance-Vested Executive Stock Options: Is Their Underreporting Under IFRS 2?, (working paper, April 2015) (finding statistically significant underreporting of compensation expense arising from grants of performance-vested stock options by German firms under the analogous accounting standard, IFRS 2); Craig W. Holden \& Daniel S. Kim, Performance Share Plans: Valuation and Optimal Design 30 \& Table 5 (working paper, March 2013) (finding that a sample of firms under-reported the grant date value of awards with an EPS metric and over-reported the value of awards with a revenue metric (both of which are accounting-based metrics)).

150 Radford, Relative Total Shareholder Return Plans: The Low-Hanging Fruit of Optimal Performance-Based Equity Design $4 \quad$ (undated), available at https://www.radford.com/relativeTsr/files/Relative_TSR_Optimal_Equity_Design.pdf.
} 
The added difficulty and unreliability of valuation are not totally unexpected. Not all performance-based plans include RPE, but introducing RPE does necessarily complicate matters. Valuing the indexed options proposed by Rappaport and others back in the 1990s would also have been more complex than valuing conventional compensatory options. Nonetheless, the retrograde move is troubling for several reasons.

First, as suggested above, difficulty in valuing performance-based equity grants ex ante makes it much more challenging to compare heterogeneous pay packages being granted to different executives at different firms, which undermines any market-based discipline being imposed on executive pay. Second, investors cannot be certain of the level of compensation being paid to their senior managers. The true expected value of this compensation is likely to be greater than firms report in their proxy statements. The SEC has recently announced rules implementing the Dodd-Frank requirement that firms disclose the ratio between CEO pay and median employee pay. ${ }^{151}$ Like others, ${ }^{152}$ I am skeptical that this innovation will do much to moderate executive pay, but I am also skeptical that the CEO pay figures - based on reported grant date compensation ${ }^{153}$ - will be accurate for CEOs receiving performance-based equity pay. ${ }^{154}$ Third, absent a tool like Black-Scholes, it is difficult for directors, investors, and participants to understand the impact of adjustments to plan terms - the tradeoffs between plan length, the number, type, and aggressiveness of performance hurdles, etc.

Moving away from valuation issues per se, investors and regulators also should be concerned that the complexity and opacity of these plans leads to gaming by boards and executives. The choice of a particular performance metric may reflect optimal matching of incentive to executive, but it could also reflect inside information on the part of executives. ${ }^{155}$ Suppose, for example, that the CEO of Acme believes that the firm's chronic under-performance with respect to sales is likely to be reversed during the next several years as a result of a number of long-term initiatives. A performance share plan based on relative sales performance would be just the ticket for the CEO and the executive team. Everyone might be happy ex post with the improved sales performance and the corresponding executive compensation, but only the

\footnotetext{
${ }^{151}$ See U.S. Securities and Exchange Commission, SEC Adopts Rule for Pay Ratio Disclosure, August 5, 2015, available at http://www.sec.gov/news/pressrelease/2015-160.html.

152 See, e.g., Steven A. Bank \& George S. Georgiev, Paying High for Low Performance (Working Paper, 2015).

153 The SEC release specifies that in calculating the pay ratio, CEO pay is to be determined in accordance with Item 402(c)(2)(x) of SEA Reg. S-K, which is the bottom line total compensation figure from the summary compensation table.

154 The SEC has also specified use of grant date pay data for its new "Pay Versus Performance" disclosure regulation, which requires firms to compare executive pay with total shareholder return. See Pay Versus Performance, SEC Release No. 34-74835; File No. S7-07-15 (April 29, 2015), 80 Fed. Reg. 26330

(May 7, 2015) ("Pay-Versus-Performance Release”), available at https://www.sec.gov/rules/proposed/2015/34-

74835.pdf. Obviously, inaccuracies in performance share award valuation would be equally troubling in this context.

155 See Yaron Amzaleg et al, CEO Control, Corporate Performance and Pay-Performance Sensitivity (working paper, 2014) (finding in a sample of Israeli companies that more powerful CEOs achieve high pay-performance sensitivity contracts during periods of strong corporate performance).
} 
executives would realize that the performance hurdle was relatively unambitious under the circumstances. Similar gaming could take place with respect to the peer group selected for relative performance evaluation. There is evidence that executive compensation peer group members are selected with an eye towards justifying higher CEO pay. ${ }^{156}$ There is little reason to think that cherry picking of this type does not take place in designing performance share plans that incorporate relative performance metrics.

Another game that firms and executives could play would be to create purposefully complex and opaque performance-based equity plans that would increase their ability to report low values for executive pay. This gaming opportunity will be discussed more fully in the following section.

\section{Accounting for Compensation Expense Arising from Performance-Based Executive Pay}

The accounting treatment of performance shares is important for two reasons. First, that treatment determines the magnitude of the single largest component, in aggregate, of executive pay as reported in the key summary compensation table in company proxy statements. The SEC mandates disclosure of the grant date value of all elements of executive pay, but the FASB determines how the "fair value" of performance shares and other equity pay awards is to be calculated. For better or worse, that table now serves as the primary benchmark for discussions of executive pay, case by case, and market wide. The second reason that the accounting treatment matters is that performance equity is not limited to the executive suite. At IBM, for example, over 500 executives receive performance shares. ${ }^{157}$ While CEO pay gets all the press, aggregate executive pay has a greater impact on reported earnings. Thus, firms are likely to care about the magnitude of grant date $\mathrm{CEO} /$ senior executive pay as well as firm-wide compensation expense, both at grant and as ultimately recorded in the books.

At present, two different accounting regimes may apply to performance share plans depending on the type of performance measures employed. ${ }^{158}$ Although the differences are not as stark as the pre-2006 difference between stock option accounting and accounting for other forms of compensation, this difference may be large enough to influence plan design. More importantly, both of the current regimes encourage under-valuation and under-reporting of executive pay, a problem that already existed with respect to conventional options, but is heightened with performance-based equity. It may be time to change course and adopt mark-tomarket accounting for these instruments and for equity pay generally.

\footnotetext{
156 Michael Faulkender \& Jun Yang, Inside the Black Box: The Role and Composition of Compensation Peer Groups, 96 J. Fin. Econ. 257 (2010) (finding that "firms appear to select highly paid peers to justify their CEO compensation”); John Bizjak et al, Are All CEOs Above Average? An Empirical Analysis of Compensation Peer Groups and Pay Design, 100 J. Fin. Econ. 538 (2011) (finding that "peer groups are constructed in a manner that biases compensation upward”).

${ }^{157}$ IBM 2015 Proxy Statement at 23.

158 See supra TAN $x$.
} 
Under US GAAP, accounting for equity compensation is governed by ASC Topic $718 .{ }^{159}$ These rules first distinguish between equity awards and liability awards. ${ }^{160}$ Grants that are settled with stock are equity awards. ${ }^{161}$ Equity awards include conventional options and restricted stock, and performance-based stock and options. Cash settled grants are liability awards. $^{162}$ Liability awards included cash-settled stock appreciation rights (SARs) ${ }^{163}$ and cashsettled performance plans, which were briefly discussed above. ${ }^{164}$

Under ASC Topic 718, liability awards are accounted for on a mark-to-market basis. ${ }^{165} \mathrm{I}$ will return to mark-to-market accounting shortly. For equity awards, compensation cost arising from an award is set equal to the fair value of the award at grant (less any amount paid for the award), and is not subsequently adjusted unless the award is modified. ${ }^{166}$ However, this cost, and the way it is recorded as an expense, differs depending on the performance measure used. ${ }^{167}$

In cases in which performance measures consist solely of share price or market metrics, such as CenturyLink's relative TSR plan, firms are required to calculate a fair value at grant, reflecting the market condition, using an appropriate model, such as a Monte Carlo simulation. ${ }^{168}$ Firms must use reasonable and supportable estimates of share price volatility, interest rates, and expected dividends as model inputs. ${ }^{169}$ The fair value that is calculated in this fashion is expensed ratably over the performance period. ${ }^{170}$ The value is not updated over time to reflect new information on the likelihood that the conditions will be satisfied, but it is adjusted for the number of shares expected not to vest because of failure to meet retention requirements. ${ }^{171}$ This is essentially the same accounting treatment that applies to conventional stock options. FASB refers to performance measures of this type as "market conditions," and I will refer to the corresponding accounting treatment as "market condition accounting" or the "market condition method.”

\footnotetext{
159 Formerly known as SFAS 123R.

160 See generally, Frederic W. Cook \& Co., Accounting for Stock Compensation under FASB ASC Topic 718 (Sept. 12, 2013) (hereinafter Cook (ASC 718)) for an overview of these accounting rules. See generally, PricewaterhouseCoopers, Guide to Accounting for Stock-based Compensation; A Multidisciplinary Approach (hereinafter PWC), for a more in depth treatment.

161 There are exceptions, but within the universe of plans considered herein, stock-settled awards are equity-based awards. See ASC 718-10-25-6; 25-19. See also, PWC at 1-18.

162 See ASC 718-10-25-6; 25-19. See also, PWC at 1-46-1-47.

163 SARs are analogous to stock options. The recipient controls the timing of exercise, but at exercise the recipient receives the "spread" on the instrument in cash.

164 Supra.

165 ASC 718-30-35; PWC at 1-13; Cook (ASC 718) at 5.

166 ASC 718-10-30; PWC at 1-13.

167 ASC 718-10-30; PWC at 1-18-1-22.

168 ASC 718-10-30-14; 718-10-55-13 to 55-20. See also PWC at 1-21 and chapter 6; Cook (ASC 718 ) at 7.

169 ASC 718-10-55-21 to 55-26. See also, PWC chapter 7. In cases in which dividends do not accrue during the performance period, the fair value of performance shares is reduced by the present value of the expected stream of dividends issued between grant and vesting. See Cook (ASC 718) at 3.

${ }^{170}$ ASC 718-10-35-2. See also, PWC at 1-24.

${ }^{171}$ ASC 718-10-30-14. See also, PWC at 1-21; Cook (ASC 718) at 7.
} 
If performance share awards include only an accounting-based performance condition, such as Coca-Cola's profit growth metric, the accounting treatment is quite different. The grant date "fair value" that is calculated for the award is not reduced to reflect the probability that the award will not vest as a result of the performance condition. ${ }^{172}$ The "fair value" per share is not an estimate of the fair value of the award at grant at all; it is simply the share price prevailing on the grant date. ${ }^{173}$ However, firms are required only to recognize an expense with respect to shares that are probable to vest. ${ }^{174}$ At grant this is often the number of shares equating to "target" performance. And any expense previously recognized for a share that was once deemed probable to vest is reversed if later it is no longer probable that the share will vest. ${ }^{175}$ In this situation, a share may not be probable to vest either because of the accounting-based performance condition or because of the retention requirement. ${ }^{176}$ Somewhat confusingly, FASB refers to performance measures of this type as "performance conditions."177 I will refer to the corresponding accounting treatment as "performance condition accounting" or the "performance condition method."

A performance share plan may incorporate both market conditions and accounting-based "performance conditions." In such a case a grant date fair value would be determined using an appropriate model that incorporates the impact of the market condition. Then, that fixed value per share would be multiplied by the number of shares that were deemed probable to vest at various points in time taking into account the accounting-based condition in order to generate the compensation expense recognized by the firm. ${ }^{178}$

\section{a. Performance Condition Accounting}

Although performance shares may include both market-based vesting hurdles and accounting-based hurdles, we will first consider the accounting issues associated with awards that include only one of these two types of conditions, beginning with accounting-based performance conditions. Presumably, FASB's failure to require firms to model and calculate a true grant date fair value for awards that incorporate accounting-based performance conditions

\footnotetext{
172 ASC 718-10-30-12, 13; PWC at 1-21; Cook (ASC 718) at 7.

${ }^{173}$ ASC 718-10-55-10; Cook (ASC 718) at 3 (full value awards) and 7 (vesting conditions). See also Coca-Cola 10$\mathrm{K}$ (for year ended 12/31/13) at 106 ("fair value of the performance share units is the quoted market value of the Company's stock on the grant date") The disclosed compensation is the product of this fair value and the number of shares probable to vest at grant. At Coke, and most other firms, this is the number of shares that will vest if target performance is achieved.

${ }^{174}$ ASC 718-10-25-20; PWC at 1-21. Outcomes are probable if "the future event(s) are likely to occur." ASC Topic 450. Where several future outcomes are possible, as in the case of performance share plans with variable numbers of shares potentially vesting, accounting accruals prior to vesting are based on the most probable outcome at any given measurement point.

${ }_{175}$ ASC 718-10-25-20; PWC at 1-21.

176 ASC 718-10-25-20, -21.

177 Per ASC 718, "performance conditions" include "performance target(s) defined solely by reference to the employer's own activities" but may also include targets "defined by reference to the same performance measure of another entity or group of entities.” ASC 718-20-20.

${ }^{178}$ See ASC 718-20-55-61, through -67 for an example.
} 
reflects skepticism that these awards can be valued accurately. ${ }^{179}$ However, the performance condition method provides firms with a great deal of discretion in reporting grant date executive pay and, depending on the payout structure, may result in a downward bias in expected compensation expense firm wide.

\section{i. Structural Bias}

Consider the following simplified relative performance share plan. After three years, Acme's CEO will receive 50,000 shares if the company achieves $25^{\text {th }}$ percentile relative performance, 100,000 shares for $50^{\text {th }}$ percentile performance, and 150,000 shares for $75^{\text {th }}$ percentile performance, with the share award linearly interpolated between $25^{\text {th }}$ and $75^{\text {th }}$ percentile performance. To simplify, we'll assume that Acme’s share price at grant is $\$ 2 /$ share, that share price and relative performance are tightly correlated, and that the overall market is flat over the three years, such that Acme's achieving $50^{\text {th }}$ percentile performance would be associated with a $\$ 2 /$ share stock price at payout as well as at grant. ${ }^{180}$ We will also assume that Acme's Time 2 share price is a linear function of percentile performance, ranging from $\$ 1 /$ share at 0 percentile performance to $\$ 3 /$ share at $100^{\text {th }}$ percentile performance. ${ }^{181}$ These assumptions are summarized in the following table:

\begin{tabular}{|l|l|l|l|}
\hline $\begin{array}{l}\text { Relative } \\
\text { Performance at } \\
\text { Time 2 }\end{array}$ & $\begin{array}{l}\# \text { of Shares } \\
\text { Vesting }\end{array}$ & $\begin{array}{l}\text { Share Price at } \\
\text { Time 1 }\end{array}$ & $\begin{array}{l}\text { Expected Share } \\
\text { Price at Time 2 }\end{array}$ \\
\hline 0 Percentile & 0 & $\$ 2$ & $\$ 1.00$ \\
\hline $25^{\text {th }}$ Percentile & 50,000 & $\$ 2$ & $\$ 1.50$ \\
\hline $50^{\text {th }}$ Percentile & 100.000 & $\$ 2$ & $\$ 2.00$ \\
\hline $75^{\text {th }}$ Percentile & 150,000 & $\$ 2$ & $\$ 2.50$ \\
\hline $100^{\text {th }}$ Percentile & 150,000 & $\$ 2$ & $\$ 3.00$ \\
\hline
\end{tabular}

I have not specified the nature of the performance condition, and, of course, that's critical under ASC 718. Let's first assume that Acme's plan is based on relative earnings per share (EPS) performance. Given the inclusion of that accounting-based performance condition (and no "market condition"), the "fair value" of the shares will be the grant date value of $\$ 2 /$ share. Recall that the "fair value" per share under this approach is simply the share price at grant. Expense recognition is based on that fair value and the number of shares that are probable to vest. $^{182}$ If the most probable outcome at grant is $50^{\text {th }}$ percentile performance, Acme will begin accruing \$200,000 of compensation expense. Over time, as Acme's performance improves or

\footnotetext{
179 See BBCK (2013) at 24, 29 (noting that techniques for valuing awards with accounting-based performance metrics "are undeveloped or nonexistent”).

${ }^{180}$ In addition to assuming that the market is flat over the performance period, I am assuming there is no time value difference between grant and payout. A more complicated model would include upward drift in share prices and a discount factor based on borrowing costs.

${ }^{181}$ The exact figures selected for this illustration are unimportant, but it is important that the share price increases and decreases associated with higher and lower relative performance are symmetric.

${ }^{182}$ Supra.
} 
regresses versus its competitors, Acme will update its expense calculation if another scenario becomes the most probable scenario, but no direct adjustment will be made for changes in share price. Ultimately, however, the expense associated with this grant will be the product of \$2/share (the "fair value" at grant) and the number of shares that actually vest. That final expense is represented by the heavily dashed line in the following figure and is labeled "performance condition accounting."

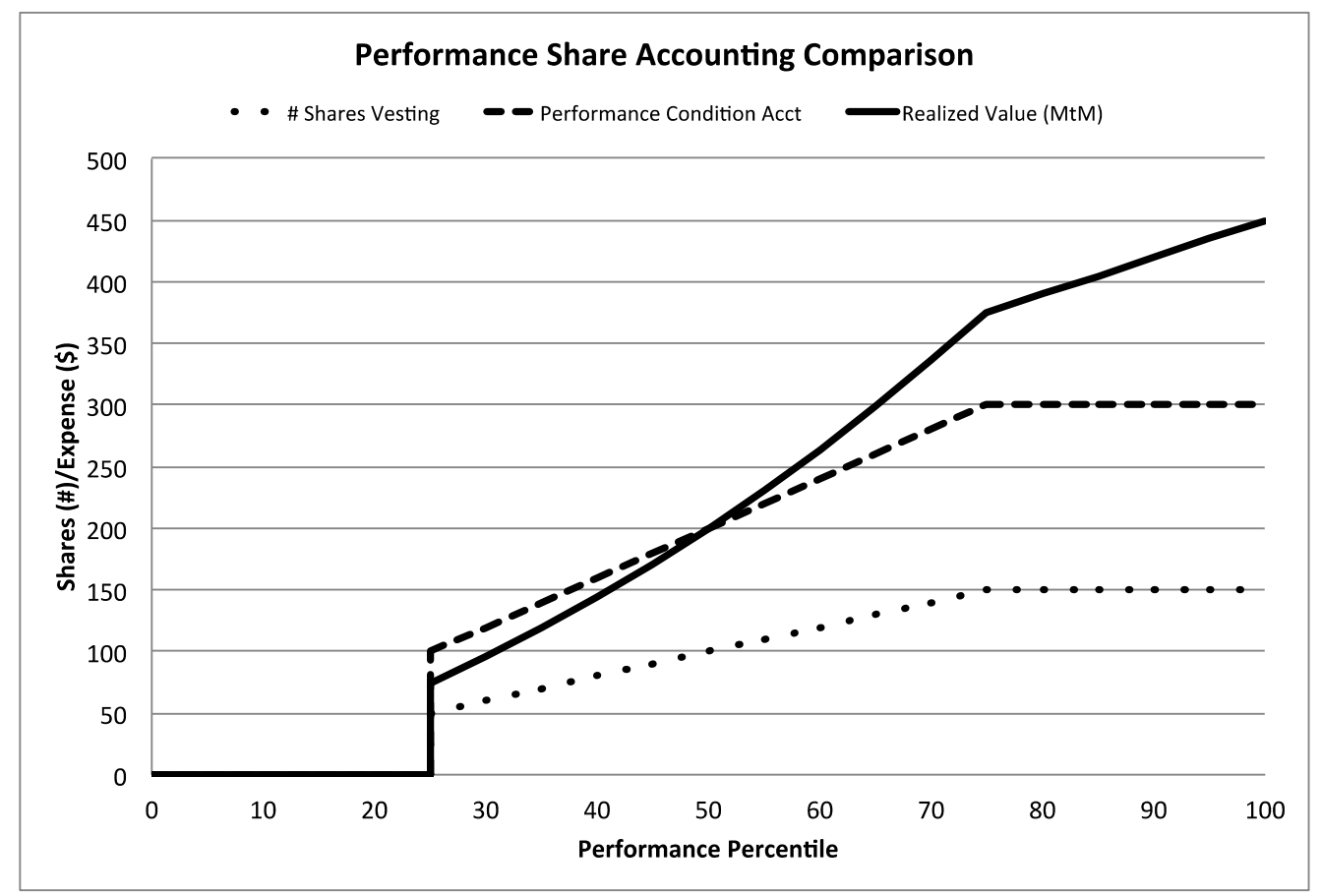

The realized value of this grant, represented by the solid line in the figure, reflects the leverage associated with performance share plans under which superior performance is linked to both more shares and more valuable shares, and inferior performance is linked to fewer, and less valuable shares. Under these assumptions, performance condition accounting results in a downward bias in expected compensation expense. Of course, we do not know what level of performance ultimately will be achieved, but if we assume a normal distribution of outcomes centered on $50^{\text {th }}$ percentile performance, it is obvious by inspection that the extent to which the performance condition accounting expense exceeds realized values between $25^{\text {th }}$ and $50^{\text {th }}$ percentile performance is more than offset by the extent to which realized values exceed the performance condition accounting expense between $50^{\text {th }}$ and $75^{\text {th }}$ percentile performance. In addition, while outcomes below $25^{\text {th }}$ and above $75^{\text {th }}$ percentile performance may be relatively rare, low outcomes result in no gap between performance condition method expense and realized values (since both are zero), while high outcomes result in significant under-valuation under the performance condition method.

Now imagine a plan identical in all ways except that the performance measure adopted is relative total shareholder return (TSR), a market condition under ASC 718. In this situation, 
Acme would use a model to determine the fair value of the grant incorporating the relative TSR hurdle. If Acme adopts unbiased model inputs, presumably the fair value under this approach would be the realized values in the figure multiplied by the probability of their occurrence. ${ }^{183}$ Acme would be required to expense that amount uniformly over the vesting period, regardless of which, if any, of the performance conditions is ultimately achieved. ${ }^{184}$ Rarely would the CEO's realized value match the compensation expense recognized by Acme, but there is no structural bias inherent in market condition accounting. Again, assuming that the simulation inputs are unbiased, an assumption we will relax below, simulation-based approaches produce unbiased compensation expense recognition.

Given the structure of the hypothesized performance share plan and my assumptions, expected compensation expense is less than the executive's expected realization. ${ }^{185}$ But what about grant date executive pay reporting? Assuming unbiased assumptions, the amount of grant date compensation disclosed would be more than the expected expense but could be more or less than the expected realized payout. In the example above, assuming $50^{\text {th }}$ percentile performance is most probable at grant date, $\$ 200,000$ of compensation would be reported for the CEO. But the expected value of the dashed, performance condition accounting line is less than $\$ 200,000$. That expected value would be exactly $\$ 200,000$ if 50,000 shares vested between 0 percentile and $25^{\text {th }}$ percentile performance. ${ }^{186}$ That would produce complete symmetry in the dashed line. But instead we have the "hockey stick" payout profile with no shares vesting until threshold performance is achieved. On the other hand, it is clear that the expected value of realized pay exceeds the expected expense. Whether that difference partially, perfectly, or over-fills the lowend gap depends on plan details. It is possible that firms disclosing grant-date values for performance share plans using this method are over-reporting executive pay levels. This phenomenon could explain, in part, BBCK's findings that firms in their sample tended to disclose performance share plan compensation, involving a single accounting-based metric, that exceeded their simulated values. ${ }^{187}$

\section{ii. Grant Date Discretion}

The structural bias inherent in the performance condition accounting method described above results in expected compensation expense being less than the expected realized value of the pay award. Minimizing this expected expense would be of interest to firms that issue

\footnotetext{
183 The expected realized value would be discounted to the grant date to determine "fair value," but in this simplified example I am ignoring time value differences between grant and payout. See supra.

184 ASC 718-10-35-2. See also, PWC at 1-24; Cook at 7.

185 Of course, performance share plans do not necessarily exhibit these features. As we have seen, one of the advantages of performance share plans is the tremendous flexibility to customize metrics to create whatever incentives a compensation committee desires to create. One could design a performance share plan for which the performance condition method results in expected compensation expense in excess of expected realized value. But the plans that I have studied tend to mirror the example considered above. Moreover, given that the performance condition method is essentially elective (through choice of performance metrics), one would expect that most firms using the performance condition method are reporting systematically low compensation expense figures.

186 Again assuming a normal distribution of outcomes centered on $50^{\text {th }}$ percentile performance.

187 BBCK (2013) at 29.
} 
performance shares widely and are concerned about minimizing aggregate compensation expense and maximizing reported earnings. But as we have seen, the impact of this structural bias on the reported level of executive pay at grant is ambiguous.

But for firms focused on minimizing disclosed grant date CEO pay, another feature of performance condition accounting looms large. This feature gives firms tremendous discretion, really unaccountable discretion, in proxy statement disclosure of ex ante executive pay.

ASC 718 instructs firms not to adjust the "fair value" of awards for the existence of performance conditions, such as the accounting-based performance metrics we have discussed. In cases in which awards carry no "market condition," the "fair value" of awards with performance conditions is simply the grant date stock price. But the associated compensation expense is this fair value multiplied by the number of shares probable to vest. ${ }^{188}$ Ultimately, this will be a certain, totally transparent figure for each grant, but at the time of the grant and in the interim between grant and vesting, firms have tremendous discretion in determining the number of shares probable to vest, and the FASB provides no specific guidance on this point.

As PricewaterhouseCoopers notes, interpretation of the term "probable" in this context should be consistent with other FASB guidance suggesting that probable means "likely to occur."189 But as PWC also notes, management judgment is required in determining whether performance conditions are likely to be achieved and, if so, at what level. ${ }^{190}$

Coca-Cola's approach appears to be typical. The value of performance shares reported in its summary executive compensation table is the product of the share price at grant and the number of shares that will vest if target performance is achieved. ${ }^{191}$ By implication, the compensation committee has determined that it is most probable that this level of profits growth will be achieved during the three-year performance period. As is typical, there is no discussion in Coke's proxy statement or $10 \mathrm{~K}$ of the basis for this particular determination.

A firm intent on minimizing reported executive pay (vis-a-vis expected compensation) would use this discretion to adopt undisclosed assumptions minimizing the most probable performance level achievement at grant. If it turns out later that performance exceeds that prediction, the executives will prosper and, indeed, the realized compensation will be reported elsewhere in the proxy statement, but the disclosure of grant date pay will remain low.

I certainly do not mean to suggest that Coca-Cola has adopted this strategy. Just the opposite appears to have been true in recent years, at least. Coke bases grant date disclosures on

\footnotetext{
188 Supra.

189 PWC at $1-21$.

190 PWC at $1-24$.

191 The Coca-Cola Company, 2014 Proxy Statement, at 63, 68.
} 
target performance levels, but it has failed to achieve that level of performance for several years. ${ }^{192}$ Coke recently has over reported grant date pay, at least in hindsight.

BBCK report that between 1998 and 2008, firms generally over-reported the grant date value of awards incorporating accounting-based metrics (relative to their own simulations). As we have seen, one reason might be that the application of the performance condition accounting approach to "hockey stick" award structures results in "most probable" grant date valuation exceeding expected payoffs. ${ }^{193}$ Another reason might be that firms are setting target levels of performance that are something of a stretch. Recall, that awards pay off, albeit at lower levels, if threshold performance targets are achieved. But if firms substitute target performance for "probable” performance at grant date, these stretch targets would result in over-reported grant date pay under this method. But there is no reason that firms cannot set stretch targets and report grant date executive pay based on more probable, even easily achievable, levels of performance.

Ultimately, some number of shares (possibly zero) will vest. Firms will have zero discretion over the ultimate compensation cost associated with performance share plans including only performance conditions. However, as long as observers focus primarily on the grant date value of executive pay packages, the discretion described above could be immensely attractive to firms with concerns about perceived levels of executive pay.

\section{b. Market Condition Accounting}

I argued above that the market condition accounting approach, which the FASB requires for performance share plans incorporating a share-price or market metric, produces an unbiased fair value as long as the inputs are unbiased. ${ }^{194}$ But there is reason to suspect that firms will adopt biased assumptions that result in systematically under-valued compensation. As noted above, firms have discretion in their choice of assumptions that feed into the models used to value instruments under a simulation-based accounting regime, and currently those assumptions are not being uniformly subjected to public scrutiny. ${ }^{195}$ Firms may employ favorable assumptions that would not stand up to close examination. In contrast to performance condition accounting, the under-valuation that results from opportunistic selection of assumptions is permanent. It affects reported grant date executive pay figures as well as the ultimate expense charged against earnings.

There is evidence that firms granting conventional stock options use their discretion in selecting assumptions with respect to stock price volatility, interest rates, and dividend yields to

\footnotetext{
192 The Coca-Cola Company, 2015 Proxy Statement, at 54 (reporting that maximum performance was achieved for the 2010-2012 performance period, but that performance has been below threshold since and is expected to be below threshold for the 2013-2015 performance period).

193 Supra.

${ }^{194}$ Supra.

${ }^{195}$ Supra.
} 
reduce the grant date fair value of these options. ${ }^{196}$ The scope to do so with respect to performance shares is even greater. Depending on the metric, more assumptions and less standard assumptions are required. For a relative TSR plan, for example, a firm would not only need an assumption as to share price volatility, but also the cross-volatility between its share price and those of its peer group, a more obscure figure that would be more difficult to confirm.

Moreover, the choice of plan metrics is unlikely to be random. Firms and managers may use inside information to select performance targets that are more easily achieved than they would appear to be to an uninformed observer. For instance, in my example above, the insiders may have reason to believe that the firm is likely to outperform its peers in total shareholder return over the relevant period such that the actual, informed probability of achieving $50^{\text {th }}$ or $75^{\text {th }}$ percentile performance is greater than random walk analysis would suggest. If so, the simulation-based market condition accounting approach, employing the stated probabilities, would produce an artificially low "fair value." Moreover, given the flexibility, opacity, and incentives to minimize reported compensation expense, we would expect under-valuation to be systematic, although perhaps not universal.

As noted above, BBCK found significant under-reporting of grant date compensation expense for a sample of share-price contingent performance awards granted between 1998 and 2012 by 750 large US companies. Reported compensation expense was $20 \%$ less than BBCK's simulated valuations. ${ }^{197}$

\section{c. How About Both?}

In combination, the forgoing sections suggest that the optimal strategy for an aggressive firm wishing to minimize expected and reported executive compensation expense would be to adopt a performance share plan with both market and accounting-based performance conditions. Consider, for example, CEO performance shares that vest only if both EPS and TSR hurdles are satisfied (the hurdles don't have to be very high). Given the TSR hurdle, the issuer would be required to use a model to determine the grant date fair value of the award, incorporating the TSR hurdle but ignoring the EPS hurdle. That exercise provides the opportunity for an aggressive firm to select model inputs that will yield a downward-biased fair value at grant. The initial expense associated with this grant and reported in the all important summary compensation table of the proxy statement will be based on this downward biased "fair value" as well as the number of shares probable to vest, given the EPS hurdle, which provides another opportunity for aggressive selection of assumptions. Ultimately, some number of shares will vest, eliminating discretion along that dimension, but given the structural downward bias inherent in performance condition accounting, the expected expense associated with such a grant will be twice reduced - once from the downward biased "fair value" and second by the asymmetric payout that is not reflected in performance condition accounting.

\footnotetext{
${ }^{196}$ Supra.

${ }^{197}$ BBCK (2013) at 21, 28, and table 3.
} 


\section{d. Firm Choice of Plan Design and Accounting Regime}

The use of performance shares is on the rise, and design practices are rapidly evolving. Most plans, however, incorporate multiple metrics and, in all likelihood, both market and performance conditions.

Among large firms, the single most popular metric for performance share plans is total shareholder return (TSR). In its survey of compensation practices at 300 large firms, the Hay Group found that $47 \%$ utilized TSR as a performance measure in $2012 .{ }^{198}$ In more recent reports, both Frederick W. Cook and Equilar have reported 58\% of sample firms utilizing a TSR measure. ${ }^{199}$ Both ISS and Glass Lewis have endorsed the use of TSR metrics, particularly relative TSR, as an effective means of tying compensation to long-term firm performance. ${ }^{200}$ Given those endorsements, the popularity of TSR metrics is not surprising.

But firms are increasingly utilizing multiple performance measures in their plans. Cook reports $55 \%$ of sample firms utilizing multiple performance measures in 2014, up from 52\% in 2012. ${ }^{201}$ Equilar reports $60 \%$ of sample firms utilizing multiple measures, ${ }^{202}$ while Hay reports $70 \%$ of sample firms utilizing multiple performance measures. ${ }^{203}$

This data does not tell us how many firms are combining market condition accounting with performance condition accounting, but it is likely to be prevalent. Cook reports that $70 \%$ of the firms in its sample that utilize a TSR metric do so in combination with a one or more financial metrics. Adopting a TSR metric triggers market condition accounting, while use of financial metrics would invoke performance condition accounting.

Moreover, despite the enduring popularity of TSR, a market metric, BBCK document the increasing popularity of accounting-based performance metrics. Between 2006 and 2012, 75$80 \%$ of the firms in BBCK's sample that granted performance-based equity incorporated an accounting-based metric in their plans, up from 55-60\% of firms that did so between 1998 and 2002. ${ }^{204}$ Consistent with these other accounts, accounting-based metrics did not necessarily displace stock price-based metrics. In BBCK's sample, use of stock-price metrics declined only modestly between 1998 and 2012. ${ }^{205}$

While the trend of adopting multiple performance metrics, and specifically, a combination of market and accounting-based performance metrics, is consistent with a story of

\footnotetext{
198 Hay (2013) at 40.

199 Cook (2014) at 12 (sample includes the 250 largest companies in the S\&P 500); Equilar (2014) at 5 (sample includes the entire S\&P 500).

${ }^{200}$ Cook (2014) at 12 (ISS).

${ }^{201}$ Cook (2014) at 13.

202 Equilar (2014) at 3.

${ }^{203}$ Hay (2013) at 41.

204 See BBCK (2013) at Table 2.

205 See BBCK (2013) at Table 2.
} 
firms selecting performance hurdles with an eye towards minimizing reported compensation expense, there are other, more benign explanations that may contribute to the observed behavior. 206

A distinct advantage to the treatment of plans with accounting-based metrics is that this regime results in zero expense recognition when performance conditions are not met (and the firm may be suffering generally) and positive expense recognition in situations in which conditions are satisfied (and the firm may be prospering). This matching or earnings smoothing may be preferred to the ratable recognition of fair value cost for share price-based performance shares regardless of ultimate outcomes. ${ }^{207}$ Core and Packard test whether firms with greater financial reporting concerns disproportionately adopt accounting-based metrics for their performance share plans in order to take advantage of this earnings smoothing, but their evidence does not support this hypothesis. ${ }^{208}$

Core and Packard also test two other hypotheses consistent with an optimal contracting explanation for performance share plan design choices - relating to the noisiness of share price and non-price metrics and stakeholder pressure - but they find no positive support for their hypotheses. $^{209}$ By contrast, Li and Wang do find evidence consistent with an optimal contracting explanation for firms adopting accounting-based performance conditions in long-term incentive plans, ${ }^{210}$ and they argue that firms "combine accounting and stock performance measures to provide more balanced long-term incentives to CEOs.”211

These stories are not mutually exclusive. Some firms may be selecting performance measures consistent solely with optimal contracting predictions while executive pay disclosure and/or more general compensation expense management considerations influence others. It would not be surprising to find firms responding to the availability of a perceived more favorable accounting treatment. Survey and other evidence indicates that executives are willing to sacrifice shareholder value to achieve favorable accounting results. ${ }^{212}$ And while causation has not been firmly established, it certainly appears in hindsight that the favorable accounting regime in the 1990s contributed significantly to the boom in the use of stock option compensation. ${ }^{213}$

\footnotetext{
${ }^{206}$ I have already mentioned the proxy advisory service thumb on the scale in favor of TSR metrics. See supra.

${ }^{207}$ John E. Core \& Heidi A. Packard, Performance Vesting Conditions and CEO Incentives 5 (working paper, Jan. 6 , 2015).

${ }^{208}$ Core \& Packard at 5.

${ }^{209}$ Core \& Packard at 23.

${ }^{210}$ Zhi Li \& Lingling Wang, Executive Compensation Incentives Contingent on Long-term Accounting Performance 3 (working paper, Nov. 17, 2014) (finding that firms are more likely to issue accounting-based performance awards when the ratio of stock volatility to accounting volatility is large).

${ }^{211} \mathrm{Li} \&$ Wang at 6.

212 See, e.g., John R. Graham et al, Value Destruction and Financial Reporting Decisions, FIN. ANALYSTS J., Nov.Dec. 2006, at 27, 31 (reporting results of a survey of over 400 CFOs indicating that over half of respondents were willing to sacrifice shareholder value in order to achieve earnings targets).

213 See supra note $\mathrm{x}$ and accompanying text.
} 
To be sure, the gap between the accounting rules applicable to share price-based and accounting-based performance plans is less dramatic than the former gap between options and restricted stock, but it may be shaping behavior, and this would be unfortunate. Compensation committees should be encouraged to optimize equity incentive plans based on maximizing shareholder returns, not minimizing reported compensation expense.

\section{Tentative Suggestions}

The numerous challenges raised by performance-based equity pay can be divided into three general categories - grant date disclosure and valuation, gaming, and accurate compensation cost accounting. One common concern is that investors and regulators may not be receiving an accurate picture of compensation cost, but another is that differences in accounting treatment or gaming opportunities may drive choices of compensation instruments, resulting only randomly, at best, in economically efficient incentive systems. Thus, uniformity should be a goal, as well as accuracy. This section will offer some tentative suggestions in each area.

\section{Grant Date Valuation and Executive Pay Disclosure}

As we have seen, the grant date valuation and disclosure challenges differ depending on whether performance equity awards include market conditions, performance conditions, or both. While valuation of market condition awards is difficult, firms are employing models that generate a grant date fair value for this class of instruments. Not all, however, disclose sufficient information to allow an analyst to replicate the valuation. CenturyLink, for example, reports in its proxy statement that "the value of performance-based restricted shares [is] based on Monte Carlo simulations in accordance with SEC rules." "14 Although a description of material assumptions is promised in the notes to financial statements, little additional information is provided there. ${ }^{215}$ We are not given the assumptions regarding the distributions of volatility of CenturyLink shares or the S\&P 500, interest rates, etc. Certainly, we are not provided with the results of the Monte Carlo simulations, aside from a final point estimate of fair value. It is not clear whether the paucity of disclosure reflects weak requirements or non-compliance with more stringent requirements, but disclosure of the underlying valuation assumptions would allow investors and other observers to judge whether and to what extent firms are minimizing reported executive pay levels by making opportunistic assumptions. ${ }^{216}$ The FASB should revisit the disclosure mandates of ASC 718 and make it clear that companies are required to disclose all inputs into these models. The only possible objection would be that firms would be forced to disclose proprietary information, but it is hard to see the risk of disclosing, e.g., estimates of

\footnotetext{
214 CenturyLink (2013 Proxy) at 53.

${ }^{215}$ CenturyLink (2013 10K) at 109-111.

${ }^{216}$ It is not clear whether the disclosure requirements are insufficient or if firms such as CenturyLink are failing to supply required disclosures. The SEC piggybacks off of FASB disclosure requirements. SEC Reg. S-K, Item 402. FASB requires disclosure of "significant assumptions used ... to estimate the fair value ... of share based compensation awards, including (if applicable)" term, expected share volatility, expected dividends, and risk-free rates. ASC 718-10-50-2(f) (emphasis added). See Merz, supra note x (finding significant failure among German listed firms to provide mandated disclosure of performance-vested stock option valuation assumptions and data).
} 
cross-volatility of share prices. These disclosures would not preclude firms from making opportunistic assumptions with respect to model inputs, but transparency should curtail the most egregious practices.

Firms are not currently modeling the impact of accounting-based performance conditions on the per share value of awards. Instead, they report grant date compensation cost based on the number of shares probable to vest, with no specific disclosure requirement attached to this analysis. Commentators suggest that this "discretion" is attractive to issuers, ${ }^{217}$ and BBCK report that firms are increasingly adopting accounting-based metrics in performance share plans. This accounting/valuation advantage could be addressed in several ways. First, FASB could mandate disclosure of the detailed process through which a firm determines the number of shares probable to vest and the assumptions underpinning that analysis. Of course, companies may be concerned that disclosure of assumptions regarding sales, earnings, etc., would jeopardize confidential information. More modestly, FASB could require companies to provide historical tabular disclosure of the performance targets that determined grant date executive pay - the most probable performance level at the time of grant - and the ultimate performance level achieved. Of course, internal and external conditions change over a performance period. We would not expect the target to be hit consistently. But if a company is regularly achieving maximum performance, while basing executive pay disclosures on target or threshold performance, that might indicate purposeful under-reporting.

More aggressively, FASB could extend the market condition method to all plans, including plans incorporating accounting-based metrics. This may not be an ideal response, as the result would likely be systematic undervaluation and underreporting of compensation expense for all performance share plans arising from opportunistic selection of model inputs. And this ignores the inherent difficulty of ex ante valuation of plans incorporating accountingbased and other non-price, non-market metrics, such as safety targets. ${ }^{218}$ On the other hand, if the problems associated with ex ante valuation of performance-based equity incorporating accounting-based performance measures could be overcome, adopting this approach would, in theory, level the accounting playing field between conventional stock and options, and performance-based equity pay, and, of course, between performance share plans incorporating different types of metrics. ${ }^{219}$

\footnotetext{
${ }^{217}$ BBCK (2013) at 7 (suggesting "flexible" accounting as a reason for shift in favor of accounting metrics); Core \& Packard at 8-9 (stating that "firms concerned about earnings targets will want the discretion that comes from" incorporation of accounting-based metrics).

${ }^{218}$ Although I have divided the world of performance share metrics into market and accounting-based metrics, the reality is more complex. To be sure, most plans involve either or both market and accounting-based metrics, but other metrics, such as safety performance, are possible, and ASC 718 more accurately divides the world of performance metrics into share price/market based and "other." ASC 718-20-20.

${ }^{219}$ I say "in theory" because the concern would remain that firms would have greater discretion to minimize reported compensation expense with respect to more complex performance-based equity pay plans than with respect to conventional options, and more discretion with respect to options than restricted stock, bonus, and salary.
} 
Highly accurate grant date valuation of these complex instruments may not be attainable. Instead of or in addition to the forgoing suggestions, the SEC should consider de-emphasizing grant date executive pay data. For example, instead of basing its new pay ratio and pay versus performance disclosures on grant date executive compensation data, the SEC could have employed a moving average of realized pay. The realized value of equity pay reflects market movements as well as compensation per se, which is why the SEC has focused historically on ex ante pay calculations in making various comparisons. But as uncertainty and gaming opportunities increase ex ante, the noisiness of ex post data may become the lesser of two evils. $^{220}$

\section{Gaming}

The gaming potential of awards incorporating performance conditions and market conditions are similar. In both cases, executives' inside information may be used to opportunistically select metrics and, when relative measures are employed, peer group membership. Gaming of performance metrics can be curtailed, but not eliminated. Investors and conscientious directors need to recognize the gaming opportunities and take steps to minimize them, or at the very least, to consider the gaming risk in thinking about the tradeoffs. For example, while it might seem more accurate to measure performance relative to that of a small group of peer companies, that selection is gameable. ${ }^{221}$ Relative performance evaluation against a broad index, such as the S\&P 500, is much less gameable. There's a tradeoff. Similarly, revising the selection of performance categories from plan to plan might be an optimal response to changes in firm priorities in a dynamic market. Sales might be the priority for the 2014 plan; earnings for the 2015 plan; and cash flow for the 2016 plan. But every time a firm chooses a new performance category or categories, there's an opportunity for executives with inside information to game the selection.

In order to minimize gaming, ideally executives would be excluded from the process of choosing peer groups and performance categories, but that is probably unrealistic. Performance metrics should reflect firm priorities, and the executives are experts on those priorities. Nonetheless, like other executive pay decisions in modern corporations, these decisions need to be managed closely by independent compensation committees and independent consultants who work directly for the independent committees. All of these people need to be finely attuned to the gaming risks.

\footnotetext{
${ }^{220}$ Executive discretion over the timing of stock option exercise also introduces noise into realized pay data, but this is not an issue with respect to performance share plans that are typically adopted annually with the same set term (most often three years) for each annual plan. In any event, a moving average of would reduce the noise in annual realized pay levels.

${ }^{221}$ Cf Faulkender \& Yang, supra note $\mathrm{x}$; Bizjak et al, supra note $\mathrm{x}$ (providing evidence of gaming in the selection of compensation peer group members).
} 


\section{Compensation Expense}

As we have seen, the two accounting methods applicable to performance share plans are both likely to result in under-reporting of compensation expense, but for different reasons. For typical plans, the performance condition method results in a downward bias in expected compensation expense (as well as discretion to minimize grant date executive pay in the proxy statement), while the market condition method opens the door for opportunistic selection of assumptions that reduce reported and expected compensation expense. Firms may prefer one of these two methods based solely on their accounting preferences, or, as we have seen, firms may adopt both by incorporating both types of performance metrics, thereby further minimizing expected compensation expense.

The two approaches are also likely to result in a significant book/tax gap with respect to executive pay. The book/tax gap refers to the difference between the amount of compensation expense reported to shareholders (book) and the amount reported to the IRS as deductible compensation expense $(\operatorname{tax}){ }^{222}$ Some commentators and several prominent politicians have argued for conforming the book and tax treatment of executive pay as a means of limiting gaming of tax deductions (also known as sheltering), expense recognition (also known as cooking the books) or both. ${ }^{223}$ Before the advent of performance-based equity compensation, stock options were the primary concern. A stock option book/tax gap arises because GAAP expense is based on a manipulable "fair value" determination at grant, while the tax deduction is based on the gain actually realized by an employee on exercise. ${ }^{224}$ Although market movements in the years between grant and exercise can result in dramatic differences between book and tax expense recognition for particular options, the only systematic concern is that book expense is being minimized through the opportunistic selection of assumptions. To be clear, to the extent that firms use unbiased assumptions in calculating grant date value, except for time value, there would be no expected difference between book and tax expense for options. ${ }^{225}$

Performance-based equity exacerbates the book/tax gap problem. As noted above, the current GAAP treatment of plans utilizing an accounting-based performance measure will result in expected book expense that is systematically less than the expected realized value of the instrument. Since tax is based on realized values, book expense will not just vary randomly from tax expense, it will be systematically lower. Performance plans that utilize only stock price measures, such as relative TSR plans, are accounted for just like options. The concern here is that the additional complexity and obscurity of these instruments will make it easier for firms to choose valuation assumptions that result in accounting expense that is downward biased. The book/tax concern with options will be magnified for these plans.

\footnotetext{
${ }^{222}$ David I. Walker \& Victor Fleischer, Book/Tax Conformity and Equity Compensation, 62 Tax Law Rev. 399, 400-03 (2009); Celia Whitaker, Bridging the Book-Tax Accounting Gap, 115 YALE L.J. 680, 684-85 (2005).

${ }^{223}$ Walker \& Fleischer, supra, at 400.

${ }^{224}$ Walker \& Fleischer, supra, at 403-06.

${ }^{225}$ The fair value of an option as calculated using Black Scholes or other accepted methodologies is the discounted present value of the expected value on realization.
} 
But there is a solution to the problem of compensation expense dis-uniformity and the book/tax gap. Several years ago, Victor Fleischer and I suggested applying mark-to-market accounting treatment to compensatory stock options. ${ }^{226}$ The idea was to ensure that the aggregate compensation expense for options matched the realized value of these instruments and to conform the book and tax treatment for options. An additional advantage to this proposal was that it reduced the benefit to firms of undervaluing options ex ante. A low ex ante valuation might reduce the level of executive pay disclosed in the proxy statement, but would not impact the ultimate book expense for compensation. As a result, firms would have less of an incentive to manipulate the ex ante value of options and less of an incentive to utilize options in the first place, over cash, restricted stock, or other forms of compensation. ${ }^{227}$

In my view, the rise of performance shares increases the attractiveness of that suggestion and increases the urgency. Under a mark-to-market approach, firms would estimate fair value at grant and begin expense accruals with that valuation. Firms would update their valuations periodically and revise accruals as necessary. In the case of options and performance share plans employing stock price or market metrics only, fair value would be recalculated periodically using the same model that firms use today at grant. In the case of performance share plans employing only accounting-based metrics, at the end of each period firms would calculate "fair value" by determining the number of shares that are probable to vest and multiplying by the current share price, not the share price at the time of the grant. For performance share plans incorporating both market and performance conditions, fair value would be recalculated by model periodically reflecting the market condition and at the same time the firm would reassess the number of shares that are probable to vest given the accounting-based performance condition. In all cases, the instruments will vest (or not) and aggregate expense recognition would be trued up to the transparent value at vesting. As a result, mark to market accounting reduces the incentive to select model inputs opportunistically to minimize valuations because these assumptions only impact initial and intermediate expense disclosures, not the ultimate book expense for performance-based equity pay.

This accounting approach is already in existence. It is the accounting treatment that applies to SARs and other "liability awards" under ASC Topic 718, including cash-settled performance plans that employ accounting-based metrics. ${ }^{228}$ In order to ensure a level playing field, this mark-to-market approach should apply to all forms of long-term compensation conventional restricted stock, options, and performance-based equity pay, in addition to SARs and cash settled performance plans.

Not only is this approach already in existence, it was the approach applicable to performance share grants prior to the issuance of SFAS $123 \mathrm{R} .{ }^{229}$ In other words, I am proposing

\footnotetext{
${ }^{226}$ Walker \& Fleischer, supra, at 436-42.

${ }^{227}$ Walker \& Fleischer, supra, at 438.

${ }^{228}$ ASC 718-30-35; PWC at 1-44.

${ }^{229}$ Core \& Packard at 7.
} 


\section{The Way We Pay Now}

a return to mark-to-market accounting for these instruments, but importantly, also for all forms of long-term compensation. ${ }^{230}$ In my view, this would be the most effective way to level the playing field between compensation instruments and ensure that book compensation expense reflects reality.

Some may argue that mark-to-market accounting creates too much uncertainty for issuers and too much noise in compensation cost recognition. ${ }^{231}$ The realized value of a performance share award, and the compensation cost recognized under mark-to-market accounting, may far exceed the value at grant if the company's stock price rises precipitously. This is true, but the problem, if it is a problem, could be managed by capping award payouts. And note that firms do not appear to be discouraged from incorporating accounting-based metrics in performance share plans, which can result today in significant variability (or noise) in the ultimate compensation expense that is booked. ${ }^{232}$ In fact, some view this feature as a plus as it tends to smooth earnings, particularly when the metric is a measure of earnings. ${ }^{233}$ But variable accounting would also tend to smooth earnings; not perfectly, of course, share prices could rise for reasons other than strong earnings. But if earnings and share price are correlated, variable accounting would serve an earnings-smoothing function.

The noise inherent in mark-to-market accounting for equity pay would reduce comparability of earnings from firm to firm and over time. This is an unavoidable downside. The question is whether we've reached the point in equity pay evolution at which mark-tomarket accounting is the lesser of two evils; whether noisiness in book expense is an acceptable price for leveling the playing field between various equity pay instruments, eliminating downward biases, and counteracting enhanced manipulability of ex ante valuation. It's a tradeoff, and the answer is not obvious. Further analysis must be left to future work. I am not concerned, however, that imposing mark-to-market accounting would kill equity pay or longterm pay more generally. ${ }^{234}$ As long as the method is applied consistently to all forms of longterm compensation, the playing field will be level and firms will be more likely to select performance metrics based on their merits. There may be some modest shift back towards salary

\footnotetext{
${ }^{230}$ Core and Packard note that SFAS 123R made performance-based equity more attractive by eliminating the markto-market or variable accounting requirement. Core \& Packard at 2. This is no doubt true. The key to my proposal would be to place all long-term compensation on an equal, mark-to-market, footing, eliminating any accounting bias between otherwise similar pay arrangements.

${ }^{231}$ Core \& Packard at 7.

${ }^{232}$ See supra (describing the increasing use of accounting-based metrics in performance share plans, which results in periodic reassessment of the number of shares probable to vest and the corresponding compensation cost). One can think of the performance condition approach as partial mark-to-market accounting. The number of shares issued is updated over time and trued up to actual, but share prices are not.

${ }^{233}$ Core \& Packard at 5.

${ }^{234} \mathrm{I}$ am also not persuaded by the argument that mark-to-market accounting is undesirable because it includes investment returns in recognized compensation cost expense. See SFAS 123R, para. B46. First, it is not clear that ex ante BSM option valuation (FASB's preferred method) does not include investment returns. Aside from time value, the real difference seems to be incorporation of expected versus actual investment returns. It is difficult, moreover, to distinguish between investment returns and returns to labor, particularly with respect to senior executive equity pay. But, again, further analysis must be left to future work.
} 
and short-term cash bonuses, but the forces lined up in favor of strengthening the link between pay and long-term performance, including the proxy advisory services, seem much too strong to countenance a significant move away from equity pay. ${ }^{235}$

\section{Conclusion}

No executive pay innovation ever seems to provide an unalloyed good, and performance-based equity is no exception. While these instruments provide tremendous flexibility and the potential to improve executive incentives - particularly through enhanced relative performance evaluation - the complexity of these instruments creates daunting challenges for our executive pay disclosure and compensation cost reporting regimes. The key, as always, is to hang onto the baby; to manage the disclosure, accounting, and gaming issues while preserving the incentive-enhancing properties of these instruments. This article has offered a few tentative suggestions along those lines, and the hope is that unpacking these instruments for a non-technical legal audience will prompt more thought and debate on appropriate and helpful regulatory responses to this evolving pay landscape.

\footnotetext{
${ }^{235}$ Some observers have voiced concern that the SEC's proposed equity pay clawback regulations may cause firms to de-emphasize equity compensation in executive pay packages. See, e.g., Morgan, Lewis \& Brockius LLP, SEC Proposes Rules Requiring Companies to Adopt, Disclose, and Comply with Clawback Policies on Erroneously Awarded Executive Compensation (July 2015) ("issues raised by the proposal are significant enough that companies may ... consider moving to more fixed compensation, time-based vesting of equity awards” etc.). In my view, the clawback regulations are unlikely to have this effect. More likely, executive pay will simply increase to offset any risk of loss via clawbacks. See generally, See U.S. Securities and Exchange Commission, SEC Proposes Rules Requiring Companies to Adopt Clawback Policies on Executive Compensation, July 1, 2015, available at http://www.sec.gov/news/pressrelease/2015-136.html.
} 